\title{
Determination of cooling rates of glasses over four orders of magnitude
}

\author{
Alex Scarani ${ }^{1}$ (1) - Alessandro Vona ${ }^{1} \cdot$ Danilo Di Genova $^{2} \cdot$ Raschid Al-Mukadam $^{3} \cdot$ Claudia Romano $^{1}$. \\ Joachim Deubener ${ }^{3}$
}

Received: 10 November 2021 / Accepted: 1 February 2022 / Published online: 1 March 2022

(c) The Author(s) 2022, corrected publication 2022

\begin{abstract}
Volcanic materials can experience up to eleven orders of magnitude of cooling rate $\left(q_{c}\right)$ starting from $10^{-5} \mathrm{~K} \mathrm{~s}^{-1}$. The glassy component of volcanic material is routinely measured via differential scanning calorimeter (DSC) to obtain $q_{c}$ through the determination of the glass fictive temperature ( $T_{f}$ ). Conventional DSC (C-DSC), which has been employed for decades, can only access a relatively small range of $q_{c}$ (from $\sim 10^{-2}$ to $\sim 1 \mathrm{~K} \mathrm{~s}^{-1}$ ). Therefore, extrapolations up to six orders of magnitude of C-DSC data are necessary to derive $q_{c}$ of glasses quenched both at extremely low and high $q_{c}$. Here, we test the reliability of such extrapolations by combining C-DSC with the recently introduced flash calorimetry (F-DSC). F-DSC enables to extend the $q_{c}$ exploration up to $10^{4} \mathrm{~K} \mathrm{~s}^{-1}$. We use three synthetic glasses as analogs of volcanic melts. We first apply a normalization procedure of heat flow data for both C-DSC and F-DSC to derive $T_{f}$ as a function of experimental $q_{c}$, following the "unified area-matching" approach. The obtained $T_{f}-q_{c}$ relationship shows that Arrhenius models, widely adopted in previous studies, are only valid for $q_{c}$ determination within the calibration range. In contrast, a non-Arrhenius model better captures $q_{c}$ values, especially when a significant extrapolation is required. We, therefore, present a practical "how-to" protocol for estimating $q_{c}$ using DSC.
\end{abstract}

Keywords Glass $\cdot$ Differential scanning calorimetry $\cdot$ Cooling rate $\cdot$ Viscosity $\cdot$ Parallel shift factor

\section{Introduction}

\section{Motivation and aims}

The estimation of the cooling rate $\left(q_{c}\right)$ embedded in volcanic glasses is pivotal for the reconstruction of their petrogenesis (Wilding et al. 1995, 1996a, b, 2000, 2004; Gottsmann and Dingwell 2001a, b, 2002; Gottsmann et al. 2004; Potuzak

Communicated by Mark S Ghiorso.

Alex Scarani

alex.scarani@uniroma3.it

1 Dipartimento di Scienze, Università degli Studi Roma Tre, Largo San L, Murialdo 1, 00146 Rome, Italy

2 Bavarian Research Institute of Experimental Geochemistry and Geophysics (BGI), University of Bayreuth, Universitätsstraße 30, 95440 Bayreuth, Germany

3 Institute of Non-Metallic Materials, Clausthal University of Technology, Zehntnerstraße 2a, 38678 Clausthal-Zellerfeld, Germany et al. 2008; Nickols et al. 2009; Kueppers et al. 2012; Helo et al. 2013; Lavallée et al. 2015; Hui et al. 2018). Indeed, the $q_{c}$ experienced by the magma controls the texture of volcanic rocks via the modulation of crystal and bubble growth with time, as well as the timescale of post-depositional processes such as sintering, welding, agglutination, rheomorphism, degassing, and crystallization (Quane et al. 2009; Shea et al. 2010; Gonnermann and Manga 2012; Di Genova et al. 2013; Vasseur et al. 2013; Vetere et al. 2015; Iezzi et al. 2017; Wadsworth et al. 2019; Cashman 2020; Giuliani et al. 2020; Di Fiore et al. 2021).

Here we present a combined conventional and flash differential scanning calorimetry (C-DSC and F-DSC) calibration by subjecting for the first time silicate melts of interest for volcanic processes to $q_{c}$ ranging between 0.08 and $30,000 \mathrm{~K} \mathrm{~s}^{-1}$. We significantly exceed the interval of $q_{c}$ previously investigated in geospeedometry studies $\left(\sim 10^{-2}\right.$ to $\left.\sim 1 \mathrm{~K} \mathrm{~s}^{-1}\right)$ and hence explore the validity of previous extrapolations from the relatively slow experimental $q_{c}$ to the realm $\left(>10 \mathrm{~K} \mathrm{~s}^{-1}\right)$ of the submarine and explosive volcanism (e.g., Potuzak et al. 2008; Nickols et al. 2009). Our study is also of particular interest for 
those melts prone to crystallization and dehydration during C-DSC measurements (Richet et al. 1996; Liebske et al. 2003; Di Genova et al. 2020a). Finally, we provide a practical "howto" guide to calculating the cooling rate of volcanic glasses.

\section{Theoretical background and experimental challenges}

Two approaches are commonly employed to estimate $q_{c}$ of the glass: (i) the first relies on the quantification of the molecular $\mathrm{H}_{2} \mathrm{O}$ and $\mathrm{OH}^{-}$species in the glass (Zhang et al. 1997, 2000; Benne and Behrens 2003; Behrens and Nowak 2003; Bauer et al. 2015; Behrens 2020) and requires knowledge of the chemical dependence of the absorption coefficients (e.g., Behrens 2020), whereas (ii) the second requires the knowledge of the limiting fictive temperature $\left[T_{f}\right.$, Tool (1946)] of the glass and can be applied both on dry and hydrous glasses. Here, we focus on the latter method that lies at the heart of the enthalpy relaxation of the melt (Wilding et al. 1995, 1996a, b, 2000, 2004; Gottsmann and Dingwell 2001a, b, 2002; Potuzak et al. 2008; Nichols et al. 2009; Helo et al. 2013; Hui et al. 2018).

The enthalpy relaxation approach is based on the observation that the glass structure depends on the cooling rate at which the parental melt crossed the glass transition interval (Tool and Eichlin 1931; DeBolt et al. 1976; Moynihan et al. 1976). Once the transition is crossed, the melt structure appears frozen at the observation timescale. The glass retains the structure and properties (e.g., enthalpy, $H$, and volume, $V$ ) of the melt at the characteristic limiting fictive temperature, $T_{f}$ (Tool 1946).

Because $T_{f}$ correlates positively with $q_{c}$ (e.g., Tool 1946; Moynihan et al. 1976), the knowledge of $T_{f}$ enables the derivation of $q_{c}$, provided that the $T_{f}$ vs. $q_{c}$ relationship is known (Zheng et al. 2019). The $T_{f}$ vs. $q_{c}$ relationship has been observed to be Arrhenian (i.e., linear in the $-\log _{10}\left(q_{c}\right)$ vs. $1 / T_{f}$ space) at $T$ close to $T_{g}$ (e.g., Webb et al. 1992; Knoche et al. 1994; Potuzak et al. 2008; Zheng et al. 2019), where $T_{g}$ is defined as the temperature at which the shear viscosity $(\eta)$ of the melt is $10^{12} \mathrm{~Pa} \mathrm{~s}$ :

$\eta\left(T_{g}\right)=10^{12} \mathrm{Pas}$

The Arrhenius correlation between $q_{c}$ and $T_{f}$ is described by the Tool (1946) equation:

$-\log _{10}\left|q_{c}\right|=-\log _{10} A_{q}+\frac{E_{a}^{q}}{2.303 R T_{f}}$

where $A_{q}$ and $E_{a}^{q}$ are fitting parameters describing the preexponential factor and the activation energy for structural relaxation, respectively, and $R$ is the gas constant. $E_{a}^{q}$ scales with the activation energy of viscous flow $\left(E_{a}^{\eta}\right.$; Moynihan et al. 1976, 1996) that, for a relatively small temperature range, can be also approximated as Arrhenian:

$\log _{10} \eta=\log _{10} A_{\eta}+\frac{E_{a}^{\eta}}{2.303 R T}$

where $A_{\eta}$ is the pre-exponential factor corresponding to the viscosity at infinite $T$ (Russell et al. 2003).

However, both descriptions of $q_{c}$ (Eq. 2) and $\eta$ (Eq. 3) are non-Arrhenian when considered across the whole $T$ range of silicate melts (Angell 1985; Hui and Zhang 2007; Giordano et al. 2008; Mauro et al. 2009; Zheng et al. 2017). The degree of deviation from the Arrhenian behavior can be described by the fragility index $m_{v i s}$, also known as kinetic melt fragility:

$\left.m_{v i s} \equiv \frac{\partial \log _{10} \eta}{\partial T_{g} / T}\right|_{T=T_{g}}$

Similarly, the degree of deviation from the Arrhenian behavior for $q_{c}$ follows the Moynihan et al. (1996) formulation:

$m_{D S C}=-\frac{E_{a}^{q}}{2.303 R T_{g}}$

Zheng et al. (2017) found that $m_{v i s}$ correlates linearly and positively with the calorimetric fragility $\left(m_{D S C}\right)$ over a wide range of kinetic fragility (varying from 26 to 108).

Different approaches have been proposed to derive $T_{f}$ of glasses. One is the Tool-Narayanaswamy-Moynihan (TNM) enthalpy relaxation geospeedometer (e.g., Tool 1946; Narayanaswamy 1971, 1988; DeBolt et al. 1976; Moynihan et al. 1976; Wilding et al. 1995), whereas others belong to the "area-matching" (or "enthalpy-matching") methodologies (Moynihan et al. 1976; Yue et al. 2002; Potuzak et al. 2008; Nichols et al. 2009; Guo et al. 2011).

The TNM approach relates $T_{f}$ to four parameters $\left(A_{q}, E_{a}^{q}\right.$ $, \beta$ and $\xi)$. It requires first multiple heat capacity measurements of the rejuvenated glass at different but matching cooling (DSC downscan) and heating (DSC upscan) cycles that allow the derivation of $A_{q}$ and $E_{a}^{q}$ (Eq. 2). Afterwards, two empirical parameters $(\beta$ and $\xi$ ) ranging between 0 and 1 are fitted by tweaking them to minimize the root square mean error to derive $T_{f}$ and thereby the unknown cooling rate $\left(q_{c}\right)$. Kenderes and Whittington (2021) have recently provided a Matlab code to derive the four kinetic parameters without the need to perform multiple heat capacity measurements. However, the TNM approach cannot model the broad exothermic enthalpy relaxation upon DSC upscan before the glass transition interval typical of hyperquenched glasses (Yue et al. 2002; Potuzak et al. 2008; Nichols et al. 2009; Zheng et al. 2019). 
The "area-matching" approaches offer a route to obtain $T_{f}$ of glasses quenched at any cooling rate. These approaches are generally based on comparing two DSC upscans (see Zheng et al. 2019 for a review). Here the glass with unknown cooling rate is heated (upscan 1) above the glass transition interval until the liquid state (i.e., $T_{f}=T$ ) to erase its thermal history. Afterwards, the rejuvenated melt is cooled $\left(q_{c}\right)$ across glass transition interval below $T_{f}$ and finally heated up (upscan 2) at the same rate $\left(q_{h}\right)$. Because here $q_{c}=q_{h}$, the onset of the calorimetric glass transition ( $T_{\text {onset }}$, Al-Mukadam et al. 2020) corresponds to $T_{f}$ (Moynihan et al. 1976; Sherer 1984; Moynihan 1993, 1995; Yue et al. 2004; Zheng et al. 2019; Di Genova et al. 2020a). $T_{\text {onset }}$ corresponds to the temperature of the crossing point between the tangent to the heat flow curve of the glass and the tangent to the inflection point on the following increase in heat flow (see "Treatment of DSC measurements and $T_{f}$ determination") (Al-Mukadam et al. 2020; Di Genova et al. 2020a; Stabile et al. 2021). Finally, upscan 1 and 2 are compared, and $T_{f}$ of the upscan 1 is obtained by a geometric reconstruction. This routine was recently refined by Guo et al. (2011) in the "unified area-matching" approach (see also "Treatment of DSC measurements and $T_{f}$ determination") for C-DSC measurements. However, this approach cannot be applied when the sample undergoes physicochemical modifications (degassing and/or crystallization) occurring in the glass transition interval during the upscan of a few K per minute typical of C-DSC (Richet et al. 1996; Liebske et al. 2003; Di Genova et al. 2020a). Although there are no studies of this effect, we hypothesize that modifications are particularly likely in iron-bearing samples prone to $\mathrm{FeO}$ nanocrystallization whose formation changes melt chemistry, increasing the melt relaxation time (Di Genova et al. 2017; 2020b). Therefore, the first aspect to be explored in this study is the applicability of the "unified area-matching" approach for calorimetric measurements performed with the new flash DSC (F-DSC, $q_{c}$ up to $5 \times 10^{4} \mathrm{~K} \mathrm{~s}^{-1}$ ) that nowadays allows the study of the relaxation processes of extremely depolymerized melts through the suppression of crystallization (Schawe and Hess 2019; Al-Mukadam et al. 2020, 2021a, b).

\section{Cooling rates ranges of volcanic glasses and literature assumptions}

Figure 1 shows a compilation of cooling rates of volcanic glasses derived by conventional Differential Scanning Calorimetry (C-DSC) measurements by both TNM and area matching approaches. These glasses experienced more than ten orders of magnitude of $q_{c}$ ranging from $\sim 10^{-5} \mathrm{~K} \mathrm{~s}^{-1}$ (agglutinate/welded materials; Wilding et al. 1995, 1996b; Gottsmann and Dingwell 2001a, 2002) to $\sim 10^{6} \mathrm{~K} \mathrm{~s}^{-1}$ (explosive submarine products; Potuzak et al. 2008; Helo et al. 2013). Glasses from a large spectrum of volcanic environments (effusive, explosive, and extra-terrestrial) experienced intermediate $q_{c}$ (Wilding et al. 1995, 1996a, b; Wilding et al. 2000; Gottsmann and Dingwell 2001a, b, 2002; Gottsmann et al. 2004; Wilding et al. 2004; Potuzak et al. 2008; Nickols et al. 2009; Kueppers et al. 2012; Helo et al. 2013; Lavallée et al. 2015; Hui et al. 2018).
Fig. 1 Compilation of C-DSC derived cooling rates of volcanic glasses from the literature, grouped according to the formation environment. Source of data: Wilding et al. (2000), Potuzak et al. (2008), Nichols et al. (2009), Kueppers et al. (2012), and Helo et al. (2013) for submarine quenched glass; Wilding et al. (1995, 1996b), Gottsmann and Dingwell (2001a, b, 2002), Gottsmann et al. (2004), and Lavallée et al. (2015) for subaerial quenched glass; Wilding et al. (2004) for subglacial quenched glass; Wilding et al. (1996a), and Hui et al. (2018) for extra-terrestrial quenched glass. The horizontal and colored areas represent the range of experimental cooling rates for C-DSC and F-DSC

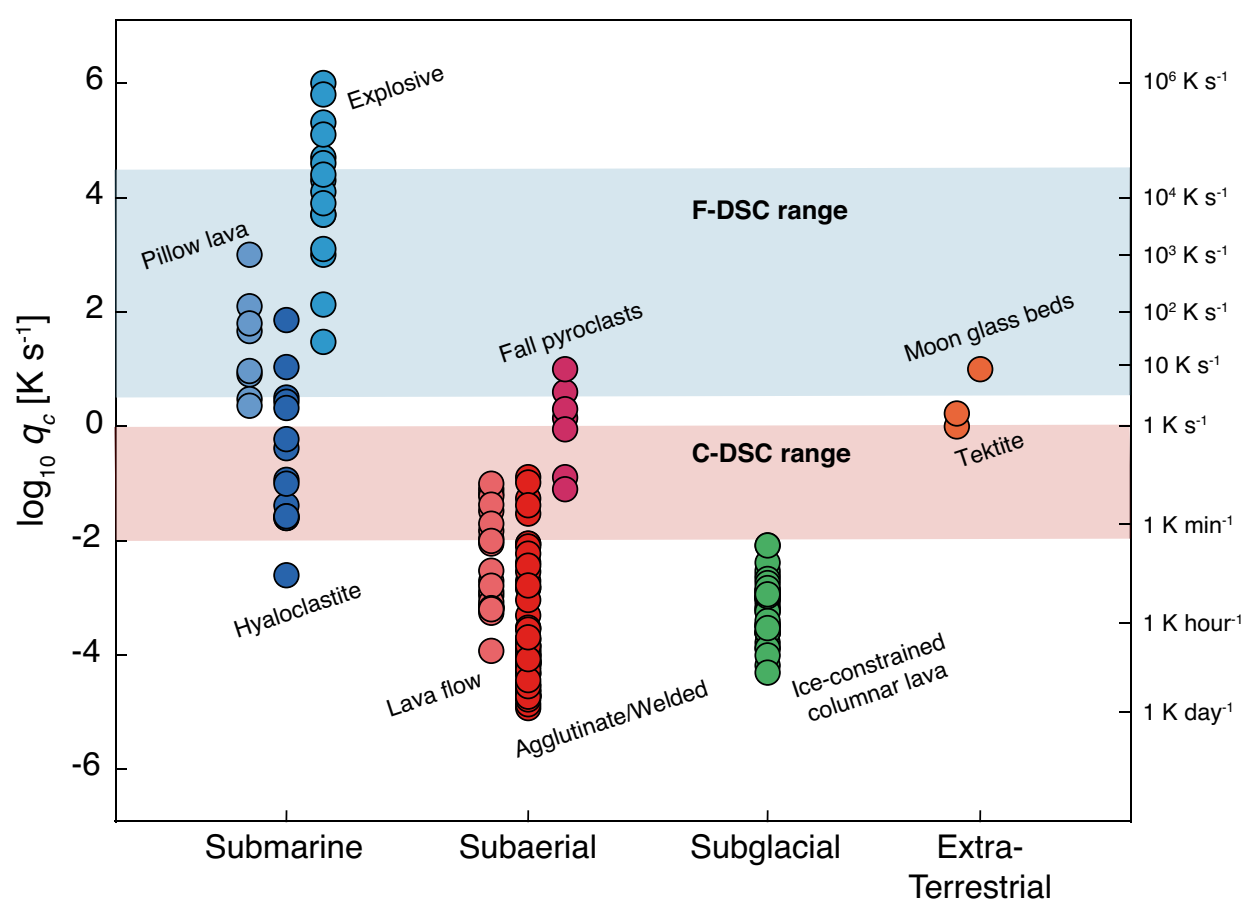


The accessible interval of $q_{c, h}$ of C-DSC equipment ranges from $\sim 10^{-2}$ to $\sim 1 \mathrm{~K} \mathrm{~s}^{-1}$ (Wilding et al. 1995, 1996b; Gottsmann and Dingwell 2001a, 2002; Helo et al. 2013; Lavallée et al. 2015; Hui et al. 2018; Al-Mukadam et al. 2020; Fig. 1). Consequently, the $T_{f}-q_{c}$ relationship calibration (Eq. 2) may require a significant Arrhenian extrapolation up to four orders of magnitude in the slow-cooling rate realm (e.g., agglutinated/welded pyroclasts), or even up to six orders of magnitude for the explosive submarine environment. Although this assumption may hold for nearly Arrhenian melts (i.e., "strong" melts after Angell 1985) where $m_{v i s}$ (Eq. 4 ) is $\sim 15$, the increase in melt fragility questions the reliability of cooling rate estimates through the Arrhenian extrapolation of Eq. 2.

As such, the second aspect to be explored in this study is the use of the F-DSC by subjecting glasses to high cooling rates and thus avoiding the extrapolation of C-DSC data to $q_{c}$ typical of the submarine and the subaerial explosive environments (Fig. 1). The significant $q_{c}$ expansion enables us to compare Arrhenian and non-Arrhenian models to describe the $T_{f}-q_{c}$ relation, within and outside the calibration range.

\section{Starting materials, experimental and analytical methods}

\section{Starting materials and their properties}

We use three glasses: a sodium-calcium silicate (DGG1, Meerlender 1974), a diopside (Di, Fanara and Behrens 2011), and a fluorophosphate (N-PK52A, Schott 2015). The chemical composition of the samples is listed in Table 1. The viscosity (Fig. 2a) and melt fragility (Fig. 2b) of these systems were characterized by Al-Mukadam et al. (2020). The melt fragility $\left(m_{v i s}\right)$ of our samples ranges from 37.8 (DGG-1) to 72.3 (N-PK52A), with the Di sample having $m_{v i s}=62.7$. Both the viscosity-temperature space and melt fragility of our melts well match the spectrum of viscosity and fragility of anhydrous and hydrous volcanic melts (shaded areas in Fig. 2) recently compiled by Langhammer et al. (2021).

The non-Arrhenian temperature dependence of viscosity (Fig. 2a) is described by VFT equations (Vogel 1921; Fulcher 1925; Tamman and Hesse 1926):

$\log _{10} \eta=A+\frac{B}{T(K)-C}$

where $A, B$, and $C$ are fitting parameters provided by Meerlender (1974) for DGG-1, by Reinsch et al. (2008) for Di, and by fitting viscometry data from Al-Mukadam et al. (2020) for N-PK52A (Supplementary Table 2). N-PK52A sample shows the lowest viscosity independently on $T$
Table 1 Chemical composition (mol\%) of the investigated glasses

\begin{tabular}{llll}
\hline Glass & DGG-1 & Di & N-PK52A \\
Ref & Meerlender (1974) & $\begin{array}{l}\text { Fanara and } \\
\text { Behrens } \\
(2011)\end{array}$ & Schott (2015) [in wt\%] \\
& \multicolumn{4}{l}{} \\
\hline $\mathrm{SiO}_{2}$ & 70.9 & 49.9 & - \\
$\mathrm{TiO}_{2}$ & 0.1 & - & - \\
$\mathrm{Al}_{2} \mathrm{O}_{3}$ & 0.7 & - & $10-20$ \\
$\mathrm{FeO}(\mathrm{T})$ & 0.1 & - & $20-30$ \\
$\mathrm{MnO}$ & - & - & - \\
$\mathrm{MgO}$ & 6.2 & 24.8 & $1-10$ \\
$\mathrm{CaO}$ & 7.1 & 25.3 & $1-10$ \\
$\mathrm{BaO}$ & - & - & $10-20$ \\
$\mathrm{SrO}$ & - & - & $10-20$ \\
$\mathrm{Na}_{2} \mathrm{O}$ & 14.3 & - & - \\
$\mathrm{K}_{2} \mathrm{O}$ & 0.2 & - & - \\
$\mathrm{Li}_{2} \mathrm{O}$ & - & - & - \\
$\mathrm{P}_{2} \mathrm{O}_{5}$ & - & - & $10-20$ \\
$\mathrm{Nb}_{2} \mathrm{O}_{5}$ & - & - & $<1$ \\
$\mathrm{SO}_{3}$ & 0.3 & - & - \\
\hline
\end{tabular}

See references for the errors in chemical analysis

(Fig. 2a). A crossover of viscosity is observed for DGG-1, and Di melts. The DGG-1 exhibits the higher viscosity only for $T$ higher than $1334 \mathrm{~K}\left(\sim 7.5 \times 10^{4} \mathrm{~K}^{-1}\right.$ on the $\mathrm{x}$-axis; Fig. 2a). This behavior results from the interplay between different melt fragility and $T_{g}$ of the melts (Fig. 2b).

\section{Differential scanning calorimetry}

The $T_{f}$ was determined by measuring the heat flow as a function of temperature using i) a C-DSC (404 F3 Pegasus)

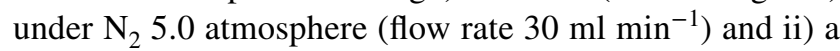
F-DSC (Flash DSC $2+$ ) equipped with the UFH 1 sensor, under constant gas flow $\left(40 \mathrm{ml} \mathrm{min}^{-1}\right)$ of Ar 5.0. The C-DSC was calibrated using melting temperature and enthalpy of fusion of reference materials (pure metals of In, Sn, Bi, Zn, $\mathrm{Al}, \mathrm{Ag}$, and $\mathrm{Au}$ ) up to $1337 \mathrm{~K}$. The mass of the glasses measured with C-DSC was $28.20 \mathrm{mg}$ for DGG-1, $22.90 \mathrm{mg}$ for $\mathrm{Di}$, and $26.60 \mathrm{mg}$ for N-PK52A. The F-DSC was calibrated using the melting temperature of aluminum (melting temperature $\left.T_{m}=933.6 \mathrm{~K}\right)$ and indium $\left(T_{m}=429.8 \mathrm{~K}\right)$. F-DSC measurements were conducted on glass chips with mass ranging from $\sim 10$ to $300 \mathrm{ng}$ depending on sample density (Al-Mukadam et al. 2020) to obtain an optimal signal-tonoise ratio.

For all measurements, 4 C-DSC and up to 14 F-DSC cycles of upscan and downscan were carried out at a fixed heating rate $\left(q_{h}\right)$ and different cooling $\left(q_{c}\right)$ rates. Heating rates imposed were $\sim 0.17 \mathrm{~K} \mathrm{~s}^{-1}\left(10 \mathrm{~K} \mathrm{~min}^{-1}\right)$ and $1000 \mathrm{~K} \mathrm{~s}^{-1}$ $\left(6 \times 10^{4} \mathrm{~K} \mathrm{~min}^{-1}\right)$ for C-DSC and F-DSC, respectively. Each 


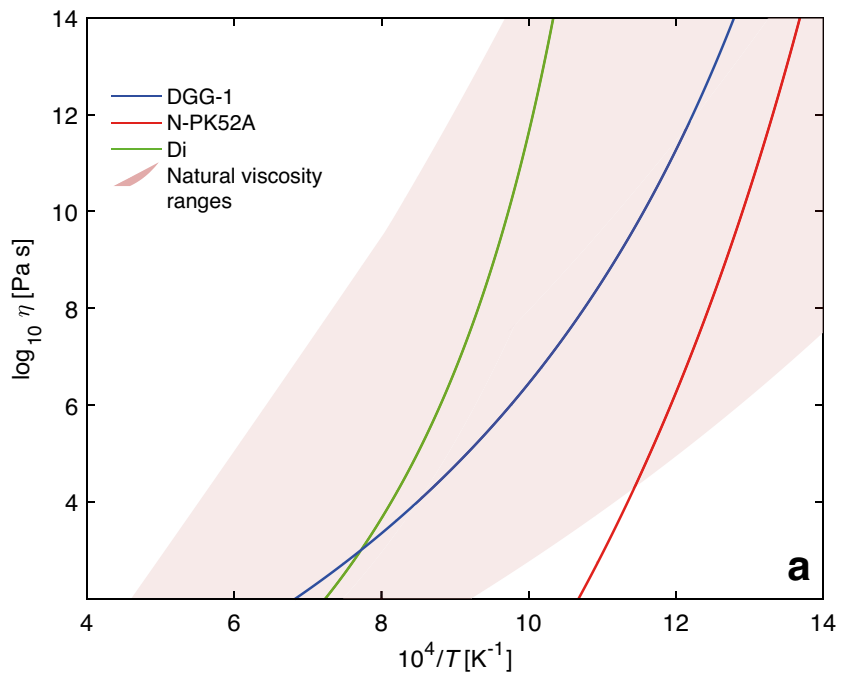

Fig. 2 a Viscosity of DGG-1, N-PK52A, and Di samples. The shaded area represents the viscosity spectrum of anhydrous and hydrous volcanic melts from Langhammer et al. (2021). b The Angell plot where the $\log _{10} \eta$ of DGG-1, N-PK52A, and Di melts is plotted against the $T_{g}$-scaled inverse temperature. The shaded area represents the same

upscan was followed by a downscan at a cooling rate ranging from $\sim 0.08$ to $\sim 0.5 \mathrm{~K} \mathrm{~s}^{-1}$ (from 5 to $30 \mathrm{~K} \mathrm{~min}^{-1}$ ) for C-DSC and from 3 to $30,000 \mathrm{~K} \mathrm{~s}^{-1}$ (from 180 to $1.8 \times 10^{6} \mathrm{~K} \mathrm{~min}^{-1}$ ) for F-DSC. Consequently, one pair of upscan and downscan was performed at the same $q_{c, h}$ of $\sim 0.17 \mathrm{~K} \mathrm{~s}^{-1}\left(10 \mathrm{~K} \mathrm{~min}^{-1}\right)$ and $1000 \mathrm{~K} \mathrm{~s}^{-1}$ for the C-DSC and F-DSC, respectively. We refer to this pair of scans as a "matching cycle".

\section{Treatment of DSC measurements and $\mathrm{T}_{f}$ determination}

The "unified area-matching" approach (Guo et al. 2011) for $T_{f}$ determination requires baseline correction and normalization. Figure 3a, c, e shows the heat flow output of C-DSC. We derived the specific heat capacity $\left(c_{P}\right.$ in $\left.\mathrm{J} \mathrm{g}^{-1} \mathrm{~K}^{-1}\right)$ using a standard sapphire (21.21 mg; Archer 1993) (Potuzak et al. 2008; Nichols et al. 2009; Hui et al. 2018). The $c_{P}$ error of the glassy contribution is $\pm 1 \%$, whereas it is $\pm 3 \%$ for the liquid state (e.g., Potuzak et al. 2008).

The glassy contribution $\left(c_{P g}\right)$ below the glass transition interval of matching cycles $\left(q_{c, h}\right)$ at $10 \mathrm{~K} \mathrm{~min}^{-1}$ (black thick curves in Fig. 3a, c, e) was fitted using the MaierKelly empirical expression (Maier and Kelly 1932) to obtain the description of $c_{P g}$ also in the glass transition interval and liquid state. We first calculated the difference between $c_{P}$ of the liquid state and $c_{P g}$ at $T_{\text {onset }}$, which here corresponds to $T_{f}$ only for matching cycles $\left(q_{c, h}=10 \mathrm{~K} \mathrm{~min}^{-1}\right.$ for C-DSC and $1000 \mathrm{~K} \mathrm{~s}^{-1}$ for F-DSCC) and specifically to $T_{g}$ when $q_{c, h}=10 \mathrm{~K} \mathrm{~min}^{-1}$ (Moynihan et al. 1976; Sherer 1984; Moynihan 1993, 1995; Yue et al. 2004; Zheng et al.

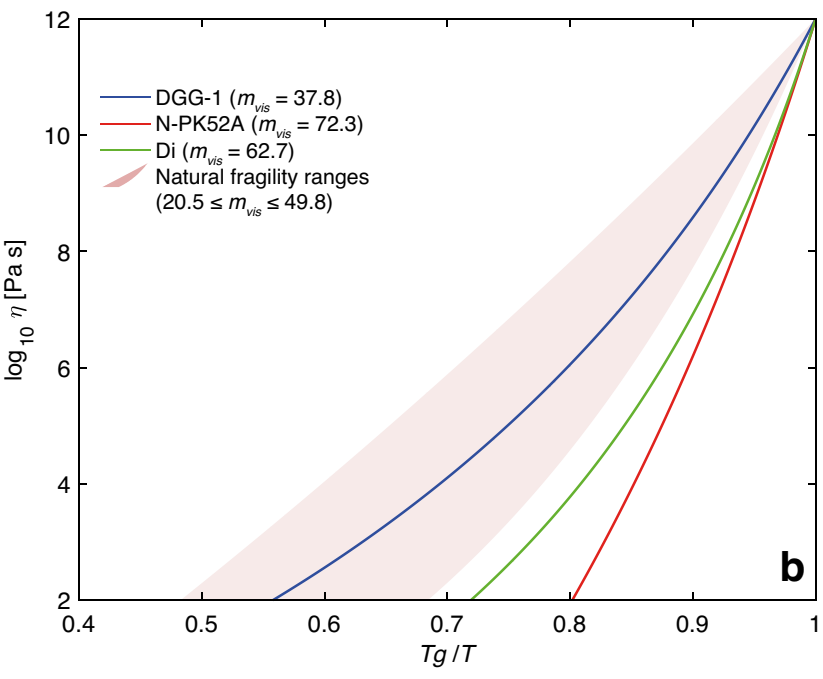

plot for anhydrous and hydrous magmatic melts where $m_{v i s}$ ranges from 20.5 to 49.8 and $T_{g}$ ranges from 814.7 to $1115.2 \mathrm{~K}$ (Langhammer et al. 2021). The fragility of our samples was estimated by AlMukadam et al. (2020)

2019; Stabile et al. 2021). This difference thus corresponds to the configuration heat capacity of the melt at $T_{g}\left[\Delta c_{P}\left(T_{g}\right)\right]$ for C-DSC. We obtained $\Delta c_{P}\left(T_{g}\right)$ equal to $0.23 \mathrm{~J} \mathrm{~g}^{-1} \mathrm{~K}^{-1}$ for DGG-1, $0.45 \mathrm{~J} \mathrm{~g}^{-1} \mathrm{~K}^{-1}$ for Di, and $0.43 \mathrm{~J} \mathrm{~g}^{-1} \mathrm{~K}^{-1}$ for N-PK52A.

Subsequently, the Maier-Kelly fit of $c_{P g}$ was subtracted from all $c_{P}$ measurements which were normalized using the $\Delta c_{P}\left(T_{g}\right)$ (Fig. 3b, d, f).

The procedure described so far was not applied to F-DSC measurements due to (1) the inability to acquire a proper background and sapphire measurements and (2) the extremely low sample mass $\left(\sim 10^{-8}-10^{-7} \mathrm{~g}\right)$ which would otherwise make the conversion of heat flow to heat capacity inaccurate (Schawe and Pogatscher 2016). Here we first applied a linear baseline over the heat flow of the glass region (Fig. 4a, c, e) and the heat flow data was subsequently converted to heat capacity (Fig. $4 \mathrm{~b}, \mathrm{~d}, \mathrm{f}$ ) using $\Delta c_{P}\left(T_{g}\right)$ from C-DSC measurements (Fig. 3) after Schawe and Pogatscher (2016).

The fictive temperature $T_{f}$ was estimated from the normalized $c_{P}$ measurements. While $T_{f} \equiv T_{\text {onset }}$ for matching cycles (Fig. 5a), $T_{f}$ of unmatching cycles was estimated according to the "unified area-matching" approach (Guo et al. 2011) as follows:

$\int_{T_{\text {onset }}}^{T_{f}}\left(\Delta C_{P}\right) d T=\int_{0}^{\infty}\left(C_{P 2}-C_{P 1}\right) d T$

where $c_{P 2}$ and $c_{P 1}$ are the normalized excess heat capacity of the matching and the unmatching cycle, respectively, and 

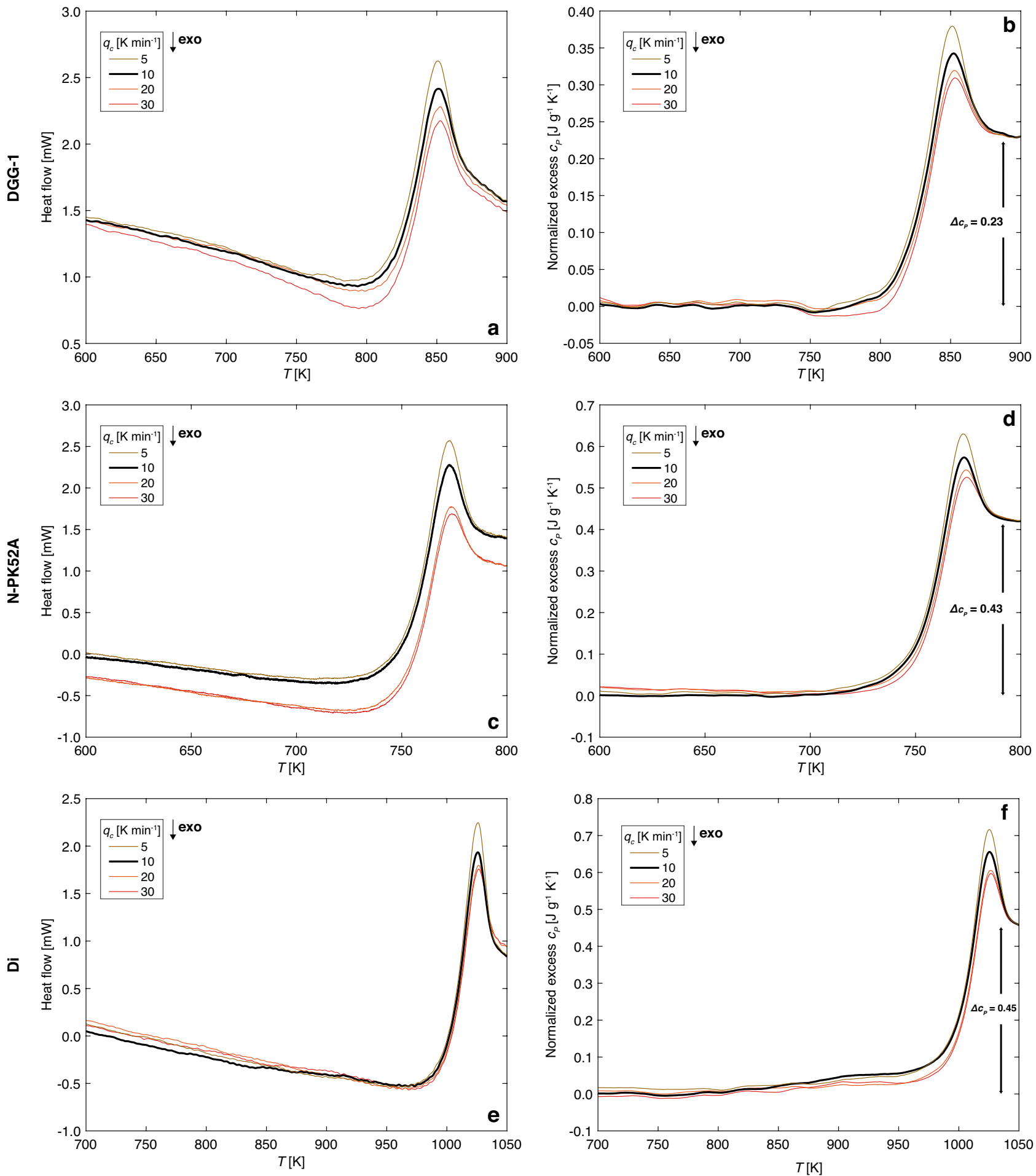

Fig. 3 C-DSC measurements (a, c, e) and treatment (b, d, f). Measured heat flow $(\mathbf{a}, \mathbf{c}, \mathbf{e})$ and normalized excess $c_{P}(\mathbf{b}, \mathbf{d}, \mathbf{f})$ of DGG-1, N-PK52A and Di samples measured at $q_{h}=10 \mathrm{~K} \mathrm{~min}^{-1}$ and variable

$q_{c}$ (from 5 to $30 \mathrm{~K} \mathrm{~min}^{-1}$ ). The matching cycle at $q_{c, h}=10 \mathrm{~K} \mathrm{~min}^{-1}$ is shown as a thick black curve. $\Delta c_{P}$ in panels $\mathbf{b}, \mathbf{d}, \mathbf{f}$ refers to to the configuration heat capacity of the melt at $T_{g}$ (see text for details) 

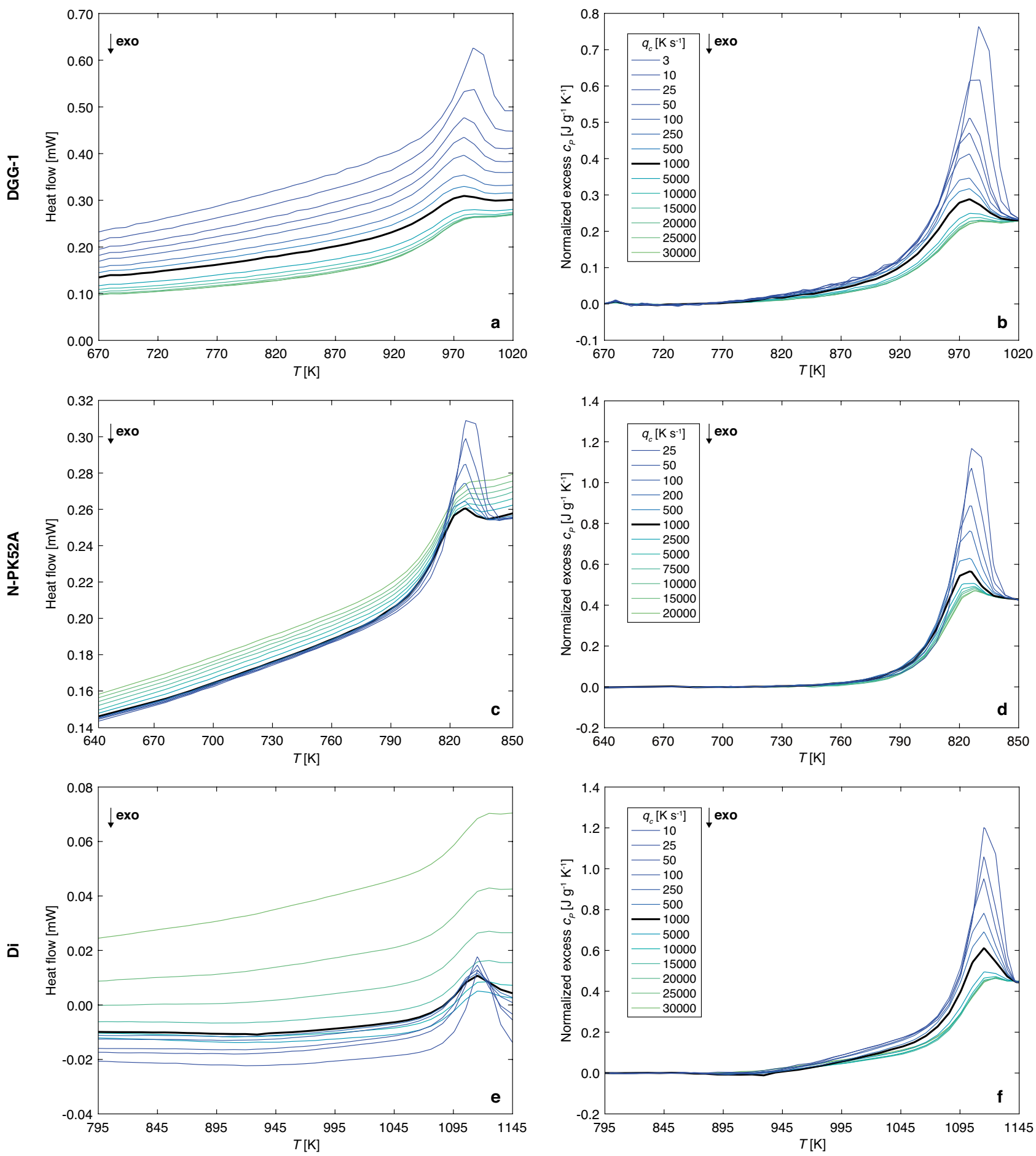

Fig. 4 C-DSC measurements (a, c, e) and treatment (b, d, f). Measured heat flow $(\mathbf{a}, \mathbf{c}, \mathbf{e})$ and normalized excess $c_{P}(\mathbf{b}, \mathbf{d}, \mathbf{f})$ of DGG-1, $\mathrm{N}-\mathrm{PK} 52 \mathrm{~A}$ and Di samples at $q_{h}=1000 \mathrm{~K} \mathrm{~s}^{-1}$ and variable $q_{c}$ (from 3

$\Delta c_{P}$ is the configurational heat capacity at $T_{g}$. The area difference between $c_{P 2}$ and $c_{P 1}$ corresponds to the rectangle whose base is defined by $T_{f}-T_{\text {onset }}$ and height by $\Delta c_{P}$ (Fig. $5 \mathrm{~b}$ ). $T_{f}$ is thus the only unknown parameter. to $30,000 \mathrm{~K} \mathrm{~s}^{-1}$ ). The matching cycle at $q_{c, h}=1000 \mathrm{~K} \mathrm{~s}^{-1}$ is showed as a thick black curve

\section{Results}

Al-Mukadam et al. (2020) determined the $T_{\text {onset }}$ (i.e., $T_{f}$ ) via matching cycles over four orders of magnitude of $q_{c, h}$ 

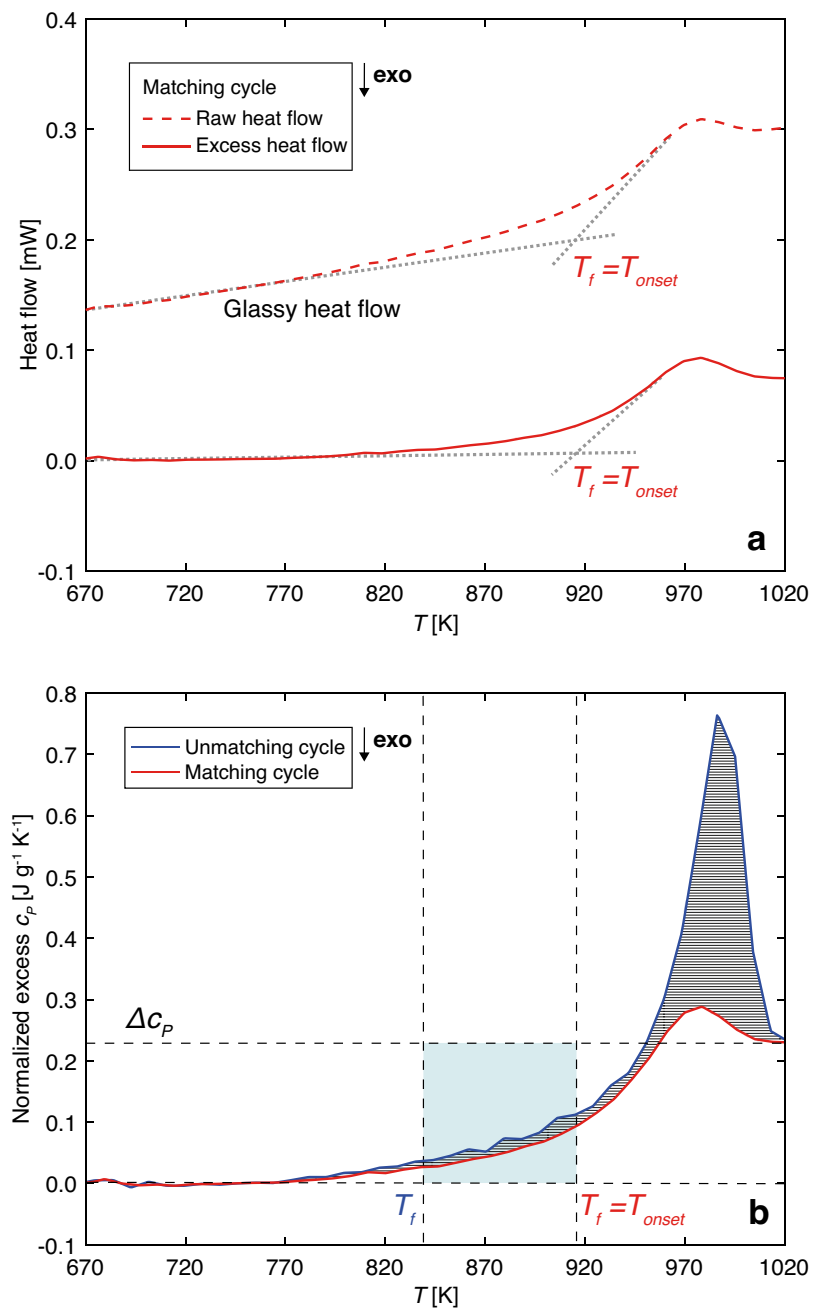

Fig. $5 T_{f}$ determination for the DGG-1 using F-DSC. a $T_{f}$ estimation for the matching cycle. Raw heat flow at $q_{c, h}=1 \times 10^{3} \mathrm{~K} \mathrm{~s}^{-1}$ (dashed line) and calculation of excess heat flow (continuous line). b Application of Eq. 7 to determine $T_{f}$ for the unmatching cycle (blue line, $\left.q_{c}=3 \mathrm{~K} \mathrm{~s}^{-1} ; q_{h}=1000 \mathrm{~K} \mathrm{~s}^{-1}\right)$. The $T_{f}$ of the matching cycle corresponds to $T_{\text {onset }}$ (see text for details)

(from $\sim 0.08 \mathrm{~K} \mathrm{~s}^{-1}$ up to $5 \times 10^{3} \mathrm{~K} \mathrm{~s}^{-1}$ ) using the same samples, C-DSC and F-DSC adopted here. We thus use their results to externally validate our strategy to derive $T_{f}$ of unmatching cycles.

We first focus on the standard glass DGG-1 whose viscosity and $T_{f}-q_{c}$ relationships are well characterized (Meerlender 1974; Al-Mukadam et al. 2020; 2021b). Figure 6a shows the temperature dependence $-\log _{10}\left(q_{c}\right)$ vs. $1 / T_{f}$ provided by Al-Mukadam et al. (2020, 2021b). They found that the $-\log _{10}\left(q_{c}\right)$ vs. $1 / T_{f}$ relationship is shifted from the VFT viscosity (left axis in Fig. 6a) by a factor of $K=11.20 \pm 0.10\left(\log _{10} \mathrm{~Pa} \mathrm{~K}\right)$ (see "Non-Arrhenian approximations" for discussion). As expected (e.g., Webb 2021), the values of $T_{\text {onset }}$ of our unmatching cycles (Table 2; triangles in Fig. 6a) strongly deviate from the main trend, which is crossed only when the matching cycle is considered (i.e., $0.17 \mathrm{~K} \mathrm{~s}^{-1}$ for C-DSC and $1000 \mathrm{~K} \mathrm{~s}^{-1}$ for F-DSC). Here $T_{\text {onset }} \equiv T_{f}$ as discussed above (see "Treatment of DSC measurements and $T_{f}$ determination").

After the normalization procedure and the application of the area-matching method, the derived $T_{f}$ from unmatching cycles (Table 2; circles in Fig. 6a) are in basic agreement with the literature data (red line in Fig. 6a) when $q_{c}<1000 \mathrm{~K} \mathrm{~s}^{-1}$. Only a small deviation of up to $-0.2 \log$ units is evident in case of F-DSC. Conversely, when $q_{c}>1000 \mathrm{~K} \mathrm{~s}^{-1}$ is considered (Fig. 6a), our results are systematically lower than the literature data. We speculate that the absence of the exothermic enthalpy relaxation event before the glass transition region (Fig. 4a, c, e), typical of hyper-quenched glasses (i.e., $q_{c} \gg q_{h}$; Yue et al. 2002; Dingwell et al. 2004), affects the area calculation of Eq. 7 that in turn leads to an underestimation of $T_{f}$ values. It thus appears that the F-DSC normalization procedure employed here (i.e., heating rate of $1000 \mathrm{~K} \mathrm{~s}^{-1}$ ) does not allow the accurate estimation of exothermic enthalpy relaxation before the glass transition interval for $q_{c}>1000 \mathrm{~K} \mathrm{~s}^{-1}$. Therefore, $T_{f}$ values when $q_{c}>1000 \mathrm{~K} \mathrm{~s}^{-1}$ were discarded and not used for the $T_{f}-q_{c}$ modeling. Overall, our results demonstrate that the "unified area-matching" strategy holds for determining $T_{f}$ when $q_{c}$ ranges between 0.08 and $1000 \mathrm{~K} \mathrm{~s}^{-1}$ using unmatching cycles. We thus conclude that this methodology can be employed also at fast cooling rates typical of F-DSC.

Table 2 lists the estimated $T_{f}$ from DSC measurements for all samples considered here. As expected (Moynihan et al. 1976), $T_{f}$ increases with increasing cooling rate. The N-PK52A sample exhibit the lowest $T_{f}$ that ranges from $746.9 \mathrm{~K}\left(0.08 \mathrm{~K} \mathrm{~s}^{-1}\right.$, C-DSC) to $804.5 \mathrm{~K}\left(20,000 \mathrm{~K} \mathrm{~s}^{-1}\right.$, F-DSC). Di sample exhibits the highest $T_{f}$ that ranges from 992.5 K (0.08 $\mathrm{K} \mathrm{s}^{-1}$, C-DSC) to $1082.0 \mathrm{~K}\left(30,000 \mathrm{~K} \mathrm{~s}^{-1}\right.$, F-DSC). The $T_{f}$ of DGG-1 melt lies in between N-PK52A and Di samples and varies between $811.8 \mathrm{~K}\left(0.08 \mathrm{~K} \mathrm{~s}^{-1}\right.$, C-DSC) and 936.7 K (30,000 $\mathrm{K} \mathrm{s}^{-1}$, F-DSC).

Figure $6 \mathrm{~b}$ shows the comparison between our $T_{f}$ and $T_{\text {onset }}$ from Al-Mukadam et al. (2020) for the three samples (see Table 2 for details). The figure illustrates an excellent agreement between the two datasets derived by C-DSC measurements, where the RMSE (Root Mean Square Error) estimated is equal to $3.0 \mathrm{~K}$. Conversely, $T_{f}$ here derived by F-DSC agrees with $T_{\text {onset }}$ from Al-Mukadam et al. (2020) when $q_{c} \leq 1000 \mathrm{~K} \mathrm{~s}^{-1}$ (RMSE $=11.4 \mathrm{~K}$ ). For $q_{c}>1000 \mathrm{~K} \mathrm{~s}^{-1}, T_{f}$ data from N-PK52A and Di glasses show a smaller departure from the 1:1 line with respect to DGG-1 data. However, in analogy to what observed for DGG-1, we decided to conservatively discard these data from further analysis. 


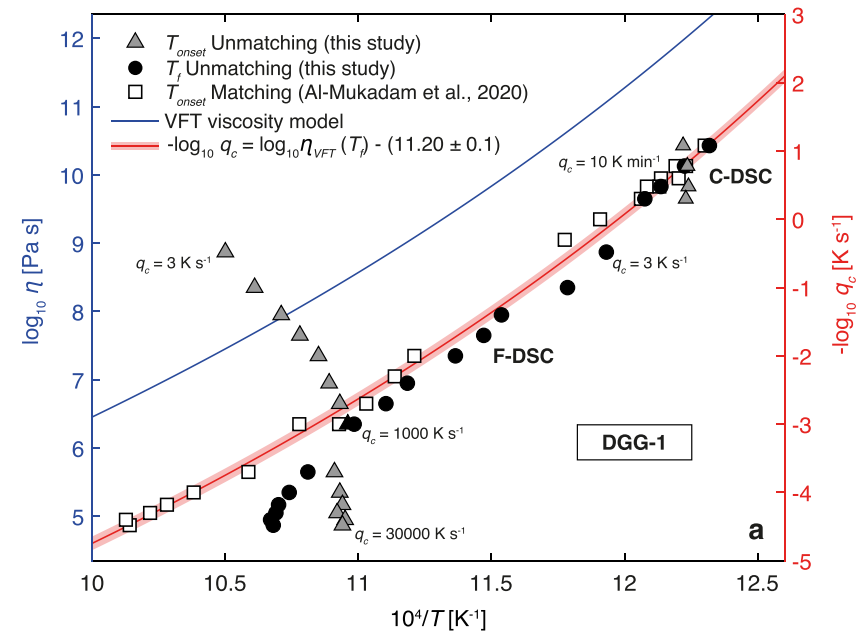

Fig. 6 Validation of strategy to calculate $T_{f}$ from unmatching cycles. a DGG-1 sample. Left axis: Arrhenius plot of viscosity (blue line) using the VFT description (Eq. 6). Right axis: Arrhenius plot of the reciprocal cooling rate. Onsets of the calorimetric glass transition ( $T_{\text {onset }}$; triangles) and characteristic fictive temperatures $\left(T_{f}\right.$; circles) obtained by DSC unmatching cycles. The onsets of the calorimetric glass transition ( $T_{\text {onset }}$; squares) from Al-Mukadam et al. (2020, 2021b) were evaluated from matching cycles and the model

\section{Discussion}

Figure 7 shows the Arrhenian plot of $-\log _{10}\left(q_{c}\right)$ vs. $10^{4} / T_{f}$ of our samples derived using both the unmatching approach employed in this study and the matching approach of AlMukadam et al. (2020). We initially fit only C-DSC data using the Arrhenian approximation of Eq. 2 (Arr. C-DSC Model). By doing this, we simulate the situation where F-DSC data (high $q_{c}$ ) are unavailable (e.g., Hui et al. 2018). Afterwards, we use Eq. 2 to fit both C-DSC and F-DSC data (Arr. C-DSC + F-DSC Model). Finally, we consider three non-Arrhenian models (non-Arr $\eta$ Model, non-Arr C-DSC Model and non-Arr C-DSC +F-DSC Model), based on the analogy between the temperature-dependence of cooling rate and viscosity (e.g., Scherer 1984; Yue et al. 2004; AlMukadam et al. 2020; Stabile et al. 2021). The non-Arr $\eta$ Model requires a priori knowledge of the viscosity-temperature relation, whereas, in non-Arr C-DSC and non-Arr $C-D S C+F-D S C$ Models, this relationship is internally calibrated based on DSC measurements.

\section{Arrhenian approximations (Arr. C-DSC and Arr. C-DSC + F-DSC models)}

When only C-DSC data are considered (Arr. C-DSC Model), we obtain activation energy $\left(E_{a}^{q}\right)$ of $619 \mathrm{~kJ} \mathrm{~mol}^{-1}$ for DGG$1,1085 \mathrm{~kJ} \mathrm{~mol}^{-1}$ for N-PK52A, and $1407 \mathrm{~kJ} \mathrm{~mol}^{-1}$ for Di (Supplementary Table 1). While this model can obviously reproduce C-DSC data (Fig. 7a), it cannot accurately

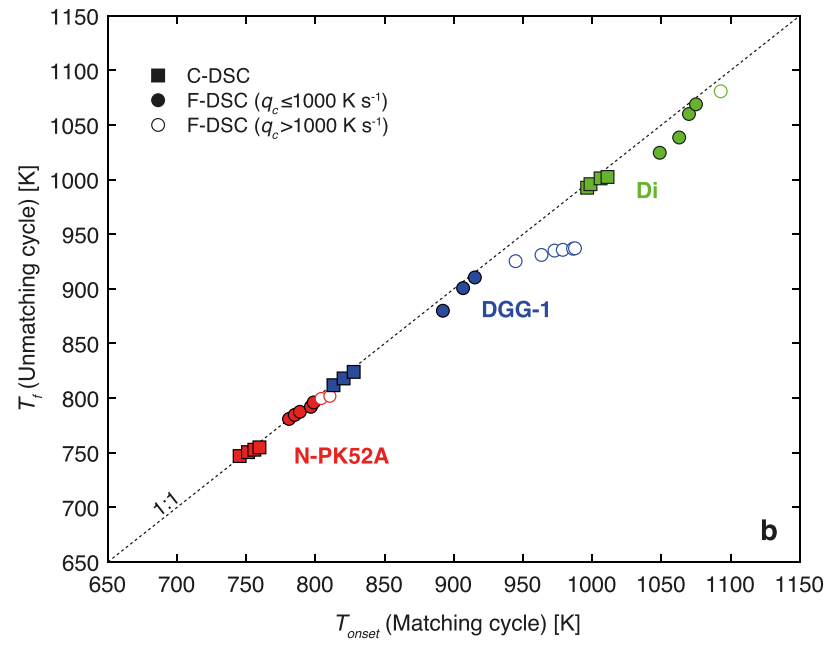

proposed by the authors relating viscosity and cooling rate (Eq. 8, with a shift factor of $K=11.20 \pm 0.10 \log _{10} \mathrm{~Pa} \mathrm{~K}$ ) are reported for reference. b Comparison between $T_{f}$ from this study and $T_{\text {onset }}$ from matching cycles by Al-Mukadam et al. (2020) for the three studied glasses (DGG-1, Di, N-PK52A). Note that only pairs of $T_{f}$ and $T_{\text {onset }}$ from measurements at the same $q_{c}$ are plotted. Results agree when $q_{c}<1000 \mathrm{~K} \mathrm{~s}^{-1}$. Data are reported in Table 2

reproduce F-DSC data. The estimated RMSE is $0.17 \log _{10}$ $\mathrm{K} \mathrm{s}^{-1}$ for DGG-1, $0.53 \log _{10} \mathrm{~K} \mathrm{~s}^{-1}$ for N-PK52A, and 0.43 $\log _{10} \mathrm{~K} \mathrm{~s}^{-1}$ for Di. The difference $\left(\Delta_{q}\right)$ between measured $\left(q_{c}\right)$ and calculated $\left(q_{c m}\right)$ cooling rates depends on the melt fragility (Fig. 7b; Table 3). For instance, when the experimental $q_{c}$ was $1000 \mathrm{~K} \mathrm{~s}^{-1}$ we obtain $q_{c m}=1727 \mathrm{~K} \mathrm{~s}^{-1}(3.24$ $\log _{10} \mathrm{~K} \mathrm{~s}^{-1}$;) for DGG-1 sample, $q_{c m}=17,019 \mathrm{~K} \mathrm{~s}^{-1}(4.23$ $\left.\log _{10} \mathrm{~K} \mathrm{~s}^{-1}\right)$ for Di and $q_{c m}=3832 \mathrm{~K} \mathrm{~s}^{-1}\left(3.58 \log _{10} \mathrm{~K} \mathrm{~s}^{-1}\right)$ for N-PK52A.

When C-DSC and F-DSC are considered (Arr. $C-D S C+F-D S C$ Model $)$, lower activation energies are obtained $\left(581 \mathrm{~kJ} \mathrm{~mol}^{-1}\right.$ for DGG-1, $923 \mathrm{~kJ} \mathrm{~mol}^{-1}$ for $\mathrm{N}-\mathrm{PK} 52 \mathrm{~A}$ and $1121 \mathrm{~kJ} \mathrm{~mol}^{-1}$ for Di; Supplementary Table 1). This results in a more accurate estimation of $q_{\mathrm{cm}}$ and thereby lower RSME (Fig. $7 \mathrm{~b}$ inset; $\mathrm{RMSE}_{\mathrm{DGG}-1}=0.14$ $\log _{10} \mathrm{~K} \mathrm{~s}^{-1} ; \mathrm{RMSE}_{\mathrm{N}-\mathrm{PK} 52 \mathrm{~A}}=0.08 \log _{10} \mathrm{~K} \mathrm{~s}^{-1} ; \mathrm{RMSE}_{\mathrm{Di}}=0.24$ $\log _{10} \mathrm{~K} \mathrm{~s}^{-1}$ ). Here, cooling rates of $q_{c m}=1278 \mathrm{~K} \mathrm{~s}^{-1}$ (3.11 $\left.\log _{10} \mathrm{~K} \mathrm{~s}^{-1}\right)$ for DGG-1, $2281 \mathrm{~K} \mathrm{~s}^{-1}\left(3.36 \log _{10} \mathrm{~K} \mathrm{~s}^{-1}\right)$ for Di, and $839 \mathrm{~K} \mathrm{~s}^{-1}\left(2.92 \log _{10} \mathrm{~K} \mathrm{~s}^{-1}\right)$ for N-PK52A are derived when the experimental $q_{c}$ is $1000 \mathrm{~K} \mathrm{~s}^{-1}$ (Table 3).

Figure 7 also shows $T_{\text {onset }}$ from Al-Mukadam et al. (2020) for comparison. Except for N-PK52A sample, both Arrhenian models fail to reproduce this dataset when $q_{c}>1000 \mathrm{~K} \mathrm{~s}^{-1}$ (Fig. 7a).

\section{Non-Arrhenian approximations}

Here we use the analogy between the $-\log _{10}\left(q_{c}\right)$ vs. $1 / T_{f}$ and the $\log _{10}(\eta)$ vs. $1 / T$ to derive $q_{c}$ when the temperature 
Table 2 Onsets of the calorimetric glass transition $\left(T_{\text {onset }}\right)$ and characteristic fictive temperatures $\left(T_{f}\right)$ of the studied glasses obtained by DSC unmatching cycles

\begin{tabular}{|c|c|c|c|c|c|c|c|c|}
\hline \multirow[t]{2}{*}{ DSC-type } & \multirow[t]{2}{*}{$q_{c}\left(\mathrm{~K} \mathrm{~s}^{-1}\right)$} & \multicolumn{3}{|l|}{ DGG-1 } & \multicolumn{2}{|c|}{$\mathrm{N}-\mathrm{PK} 52 \mathrm{~A}$} & \multicolumn{2}{|l|}{ Di } \\
\hline & & $T_{\text {onset (unmatching) }}(\mathrm{K})$ & $T_{f}(\mathrm{~K})$ & ${ }^{\sharp} T_{\text {onset (matching) }}(\mathrm{K})$ & $T_{f}(\mathrm{~K})$ & ${ }^{\sharp} T_{\text {onset (matching) }}(\mathrm{K})$ & $T_{f}(\mathrm{~K})$ & ${ }^{\#} T_{\text {onset (matching) }}(\mathrm{K})$ \\
\hline \multirow[t]{4}{*}{ C-DSC } & 0.08 & 818.7 & 811.8 & 813.0 & 746.9 & 745.2 & 992.5 & 996.3 \\
\hline & 0.17 & 818.0 & 818.0 & 820.3 & 750.5 & 751.2 & 995.8 & 998.7 \\
\hline & 0.33 & 818.2 & 824.0 & 827.6 & 752.7 & 755.8 & 1001.1 & 1006.0 \\
\hline & 0.50 & 818.3 & 828.1 & - & 754.9 & 759.5 & 1002.4 & 1011.0 \\
\hline \multirow[t]{20}{*}{ F-DSC } & 3 & 952.3 & 838.1 & - & - & - & - & - \\
\hline & 10 & 942.5 & 848.5 & - & - & - & - & - \\
\hline & 25 & 933.6 & 866.7 & - & 778.9 & - & 1024.5 & 1048.8 \\
\hline & 50 & 927.3 & 871.8 & - & 780.9 & 780.9 & 1031.6 & - \\
\hline & 100 & 921.4 & 879.9 & 892.1 & 784.6 & 785.0 & 1038.5 & 1062.8 \\
\hline & 200 & - & - & 898.0 & 787.4 & 788.7 & - & 1061.3 \\
\hline & 250 & 918.5 & 894.1 & - & - & - & 1048.9 & - \\
\hline & 500 & 914.6 & 900.6 & 906.7 & 792.0 & 796.7 & 1060.0 & 1069.9 \\
\hline & 750 & - & - & - & - & - & - & 1072.8 \\
\hline & 1000 & 912.3 & 910.4 & 915.2 & 796.0 & 798.7 & 1068.9 & 1074.9 \\
\hline & 1500 & - & - & - & - & - & - & 1080.0 \\
\hline & 2000 & - & - & - & - & - & - & 1084.1 \\
\hline & 2500 & - & - & - & 799.6* & 804.1 & - & - \\
\hline & 5000 & $916.6^{*}$ & $925.3^{*}$ & 944.6 & $801.7 *$ & 810.4 & $1080.8^{*}$ & 1092.8 \\
\hline & 7500 & - & - & - & $803.5^{*}$ & - & - & - \\
\hline & 10,000 & $914.6^{*}$ & $931.0^{*}$ & 963.3 & $802.9^{*}$ & - & $1086.4 *$ & - \\
\hline & 15,000 & $914.2^{*}$ & $935.0^{*}$ & 972.7 & $804.1^{*}$ & - & $1088.3^{*}$ & - \\
\hline & 20,000 & $916.1^{*}$ & $935.7 *$ & 978.7 & $804.5^{*}$ & - & $1086.7 *$ & - \\
\hline & 25,000 & $913.1^{*}$ & $937.1^{*}$ & 987.5 & - & - & $1082.5^{*}$ & - \\
\hline & 30,000 & $914.0^{*}$ & $936.7 *$ & 986.1 & - & - & $1081.0 *$ & - \\
\hline
\end{tabular}

Onsets of the calorimetric glass transition $\left(T_{\text {onset }}\right)$ from DSC matching cycles by Al-Mukadam et al. (2020) are reported for comparison. Stars $(*)$ indicate data excluded from subsequent analyses (see text for details)

dependence of viscosity is known. This analogy builds on the equivalence between the activation energy for viscous flow $\left(E_{a}^{\eta}\right)$ and the activation energy for structural relaxation $E_{a}^{q}$ determined by DSC (Scherer 1984; Moynihan et al. 1996; Al-Mukadam et al. 2020, 2021a, b; Di Genova et al. 2020a). Scherer (1984) first proposed a parallel shift factor correlating viscosity and $q_{c}$ following the equation:

$K=\log _{10}\left(\left|q_{c}\right|\right)+\log _{10} \eta\left(T_{f}\right)$

where $\eta\left(T_{f}\right)$ is the viscosity at $T_{f}$.

In the following, we examine two cases: (i) $\log _{10}(\eta)$ at $T_{f}$ is independently known (non-Arr. $\eta$ Model) and (ii) $\log _{10}(\eta)$ at $T_{f}$ is derived from C-DSC and F-DSC data (non-Arr. C-DSC Model, and non-Arr. C-DSC+F-DSC Model).

\section{Viscosity is independently known (non-Arr. $\eta$ Model)}

The viscosity-temperature dependence of melts used here is known (Al-Mukadam et al. 2020) over a large interval $\left(\sim 10^{1}<\eta<\sim 10^{12} \mathrm{~Pa} \mathrm{~s}\right)$ and described by the non-Arrhenian VFT equation (Eq. 6; Supplementary Table 2). Therefore, $T_{f}$ can be used to calculate $\eta\left(T_{f}\right)$ and obtain $K$ (Eq. 8; Supplementary Fig. 1). We use either the C-DSC subset, the F-DSC subset, or the entire dataset (C-DSC + F-DSC). Slightly different $K$ values are obtained for different samples and DSC devices (Supplementary Tables 2 and 3). The lowest mean value $\left(11.11 \pm 0.06 \log _{10} \mathrm{~Pa} \mathrm{~K}\right)$ is calculated for Di (only C-DSC data), while the highest $(11.49 \pm 0.09$ $\log _{10} \mathrm{~Pa} \mathrm{~K}$ ) for DGG-1 (only F-DSC). By combining C-DSC and F-DSC data, we obtain $K=11.40 \pm 0.15 \log _{10}$ $\mathrm{Pa} \mathrm{K}$ for DGG, $K=11.34 \pm 0.11 \log _{10} \mathrm{~Pa} \mathrm{~K}$ for N-PK52A and $K=11.30 \pm 0.20 \log _{10} \mathrm{~Pa} \mathrm{~K}$ for Di. We thus provide a global value of $K=11.35 \pm 0.16 \log _{10} \mathrm{~Pa} K$ that agrees with previous data within the standard deviation $(11.20 \pm 0.10$ $<K<11.35 \pm 0.10$; Scherer 1984; Yue et al. 2004; Chevrel et al. 2013; Shawe and Hess, 2019; Al-Mukadam et al. 2020, 2021b; Di Genova et al. 2020b; Stabile et al. 2021).

The $K_{\text {mean }}=11.35 \log _{10} \mathrm{~Pa} \mathrm{~K}$ allows the estimation of $q_{c}$ up to $1000 \mathrm{~K} \mathrm{~s}^{-1}$ with a RMSE of $0.15 \log _{10}$ 

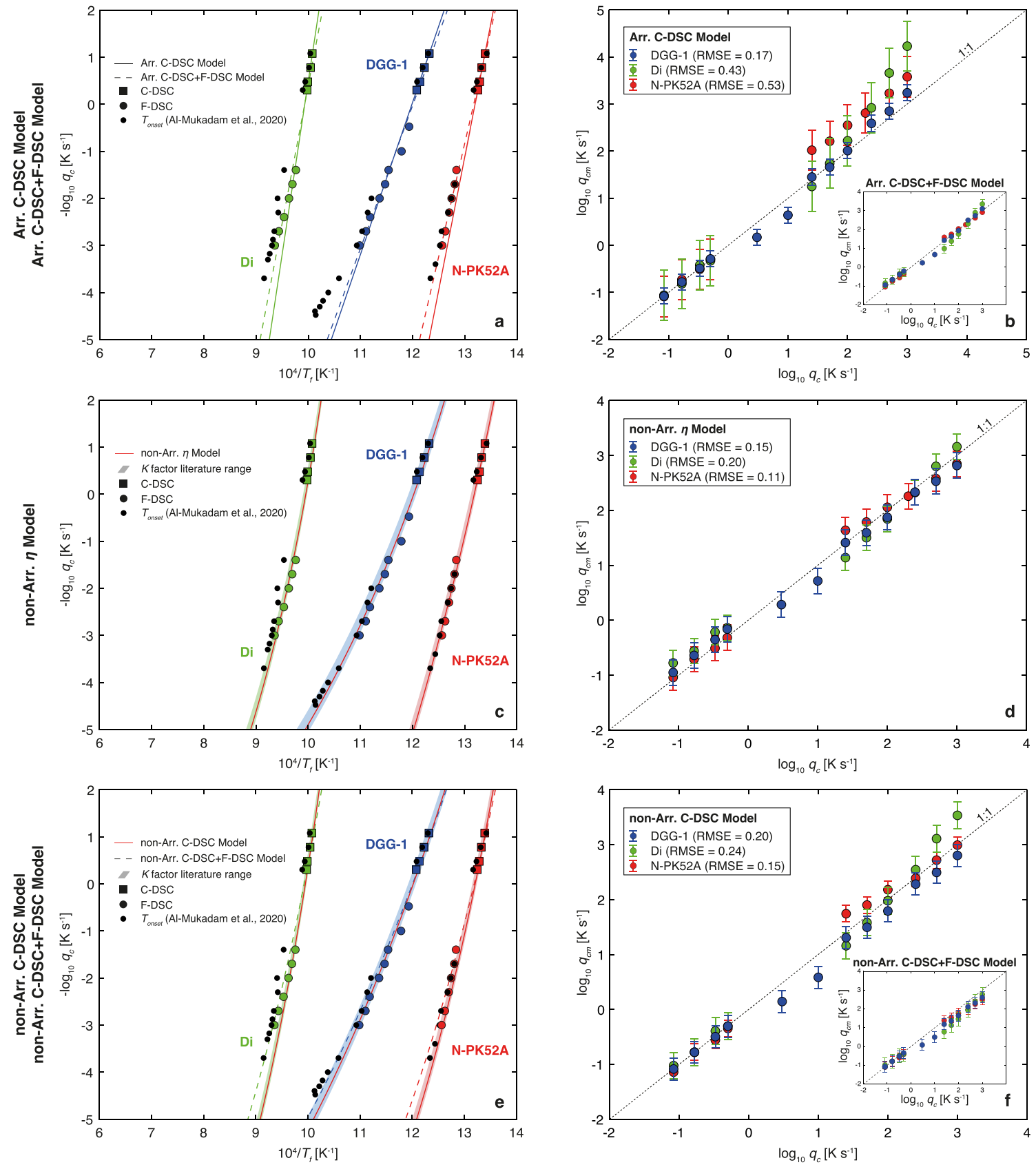

Fig. 7 C-DSC (squares) and F-DSC (circles) data, their modeling (a, c, e). In a, c, and e, data from Al-Mukadam et al. (2020) are reported for comparison purpose (small black circles). a Solid and dashed lines represent the Arrhenian models based only on C-DSC data (Arr. C-DSC Model) and the combination of C-DSC and F-DSC data (Arr. C-DSC+F-DSC Model), respectively. c, e Non-Arrhenian fitting of data according to Eq. 8, using $\mathbf{c}$ the VFT equation (Eq. 6) (non-Arr. $\eta$ Model) and e internally calibrated (C-DSC-based and C-DSC + F-DSC-based) MYEGA equation (Eq. 10) (non-Arr. C-DSC
Model, solid lines; non-Arr. C-DSC +F-DSC Model, dashed lines). Red lines correspond to Eq. 8 (where $K_{\text {mean }}=11.35 \log _{10} \mathrm{~Pa} \mathrm{~K}$ as derived in this study). Shaded areas correspond to the $K_{\text {mean }}$ uncertainty $\left( \pm 0.16 \log _{10} \mathrm{~Pa} \mathrm{~K}\right)$. b, d, f Experimentally imposed $\left(q_{c}\right)$ vs. modelled $\left(q_{c m}\right)$ cooling rates for the different models: b Arr. C-DSC Model (Arr. C-DSC+F-DSC Model is reported in the inset); d nonArr. $\eta$ Model; e non-Arr. C-DSC Model (non-Arr. C-DSC+F-DSC Model is reported in the inset). Dotted lines represent the 1:1 line; all calculated data are reported with relative standard deviations 
Table 3 Cooling rates estimated $\left(q_{c m}\right)$ according to the different model proposed in this study

\begin{tabular}{|c|c|c|c|c|c|c|c|}
\hline \multirow[t]{2}{*}{ Sample } & \multirow[t]{2}{*}{ DSC-type } & \multirow[t]{2}{*}{$\log _{10} q_{c}\left(\mathrm{~K} \mathrm{~s}^{-1}\right)$} & \multirow{2}{*}{$\begin{array}{l}\text { Arr. C-DSC Model } \\
\log _{10} q_{c m}\left(\mathrm{~K} \mathrm{~s}^{-1}\right) \\
\end{array}$} & \multirow{2}{*}{$\begin{array}{l}\text { Arr. C-DSC+F-DSC } \\
\text { Model } \\
\log _{10} q_{c m}\left(\mathrm{~K} \mathrm{~s}^{-1}\right)\end{array}$} & \multirow{2}{*}{$\begin{array}{l}\text { non-Arr. } \eta \text { Model } \\
\log _{10} q_{c m}\left(\mathrm{~K} \mathrm{~s}^{-1}\right)\end{array}$} & \multirow{2}{*}{$\begin{array}{l}\text { non-Arr. C-DSC } \\
\text { Model } \\
\log _{10} q_{c m}\left(\mathrm{~K} \mathrm{~s}^{-1}\right) \\
\end{array}$} & \multirow{2}{*}{$\begin{array}{l}\text { non-Arr. } \\
\text { C-DSC +F-DSC } \\
\text { Model } \\
\log _{10} q_{c m}\left(\mathrm{~K} \mathrm{~s}^{-1}\right) \\
\end{array}$} \\
\hline & & & & & & & \\
\hline \multirow[t]{13}{*}{ DGG-1 } & \multirow[t]{4}{*}{ C-DSC } & -1.08 & -1.08 & -0.95 & -0.95 & -1.09 & -1.07 \\
\hline & & -0.78 & -0.78 & -0.66 & -0.64 & -0.78 & -0.78 \\
\hline & & -0.48 & -0.49 & -0.39 & -0.35 & -0.50 & -0.51 \\
\hline & & -0.30 & -0.29 & -0.21 & -0.16 & -0.31 & -0.33 \\
\hline & \multirow[t]{9}{*}{ F-DSC } & 0.48 & 0.17 & 0.23 & 0.28 & 0.14 & 0.09 \\
\hline & & 1.00 & 0.64 & 0.67 & 0.72 & 0.58 & 0.51 \\
\hline & & 1.40 & 1.45 & 1.43 & 1.41 & 1.31 & 1.19 \\
\hline & & 1.70 & 1.66 & 1.63 & 1.59 & 1.50 & 1.37 \\
\hline & & 2.00 & 2.01 & 1.95 & 1.87 & 1.79 & 1.65 \\
\hline & & 2.40 & 2.59 & 2.50 & 2.33 & 2.28 & 2.12 \\
\hline & & 2.70 & 2.85 & 2.74 & 2.53 & 2.49 & 2.32 \\
\hline & & 3.00 & 3.24 & 3.11 & 2.82 & 2.80 & 2.62 \\
\hline & & & $\mathrm{RMSE}=0.17$ & $\mathrm{RMSE}=0.14$ & $\mathrm{RMSE}=0.15$ & $\mathrm{RMSE}=0.20$ & $\mathrm{RMSE}=0.29$ \\
\hline \multirow[t]{11}{*}{ N-PK52A } & \multirow[t]{4}{*}{ C-DSC } & -1.08 & -1.09 & -1.05 & -1.04 & -1.14 & -1.09 \\
\hline & & -0.78 & -0.73 & -0.75 & -0.71 & -0.78 & -0.78 \\
\hline & & -0.48 & -0.51 & -0.56 & -0.51 & -0.56 & -0.59 \\
\hline & & -0.30 & -0.30 & -0.38 & -0.32 & -0.35 & -0.41 \\
\hline & \multirow[t]{7}{*}{ F-DSC } & 1.40 & 2.02 & 1.59 & 1.64 & 1.74 & 1.39 \\
\hline & & 1.70 & 2.21 & 1.75 & 1.79 & 1.90 & 1.53 \\
\hline & & 2.00 & 2.55 & 2.04 & 2.06 & 2.18 & 1.78 \\
\hline & & 2.30 & 2.81 & 2.26 & 2.26 & 2.39 & 1.96 \\
\hline & & 2.70 & 3.23 & 2.62 & 2.58 & 2.72 & 2.25 \\
\hline & & 3.00 & 3.58 & 2.92 & 2.85 & 2.99 & 2.50 \\
\hline & & & $\mathrm{RMSE}=0.43$ & $\mathrm{RMSE}=0.08$ & $\mathrm{RMSE}=0.11$ & $\mathrm{RMSE}=0.15$ & $\mathrm{RMSE}=0.26$ \\
\hline \multirow[t]{11}{*}{ Di } & \multirow[t]{4}{*}{ C-DSC } & -1.08 & -1.06 & -0.85 & -0.78 & -1.02 & -0.97 \\
\hline & & -0.78 & -0.82 & -0.66 & -0.56 & -0.78 & -0.78 \\
\hline & & -0.48 & -0.42 & -0.35 & -0.22 & -0.39 & -0.47 \\
\hline & & -0.30 & -0.33 & -0.28 & -0.14 & -0.30 & -0.40 \\
\hline & \multirow[t]{7}{*}{ F-DSC } & 1.40 & 1.25 & 0.99 & 1.14 & 1.16 & 0.79 \\
\hline & & 1.70 & 1.74 & 1.38 & 1.50 & 1.58 & 1.13 \\
\hline & & 2.00 & 2.22 & 1.76 & 1.84 & 1.98 & 1.47 \\
\hline & & 2.40 & 2.92 & 2.31 & 2.32 & 2.54 & 1.94 \\
\hline & & 2.70 & 3.66 & 2.90 & 2.80 & 3.11 & 2.41 \\
\hline & & 3.00 & 4.23 & 3.36 & 3.16 & 3.53 & 2.78 \\
\hline & & & $\mathrm{RMSE}=0.53$ & $\mathrm{RMSE}=0.24$ & $\mathrm{RMSE}=0.20$ & $\mathrm{RMSE}=0.24$ & $\mathrm{RMSE}=0.37$ \\
\hline
\end{tabular}

Bold numbers highlight matching cycle measurements

$\mathrm{K} \mathrm{s}^{-1}$ for DGG-1, $0.20 \log _{10} \mathrm{~K} \mathrm{~s}^{-1}$ for Di, and 0.11 $\log _{10} \mathrm{~K} \mathrm{~s}^{-1}$ for N-PK52A. For instance, the non-Arr. $\eta$ Model returns $q_{c m}=655 \mathrm{~K} \mathrm{~s}^{-1}\left(2.82 \log _{10} \mathrm{~K} \mathrm{~s}^{-1}\right)$ for DGG-1, $q_{c m}=1443 \mathrm{~K} \mathrm{~s}^{-1}\left(3.16 \log _{10} \mathrm{~K} \mathrm{~s}^{-1}\right)$ for Di, and $q_{c m}=705 \mathrm{~K} \mathrm{~s}^{-1}\left(2.85 \log _{10} \mathrm{~K} \mathrm{~s}^{-1}\right)$ for N-PK52A, when the experimental $q_{c}$ is $1000 \mathrm{~K} \mathrm{~s}^{-1}$ (Table 3; Fig. 7d).

Notably, the non-Arr $\eta$ Model excellently fits the $T_{\text {onset }}$ from Al-Mukadam et al. (2020) up to $30,000 \mathrm{~K} \mathrm{~s}^{-1}$ within the error (Fig. 7c).

\section{Viscosity is internally calibrated by DSC measurements} (non-Arr. C-DSC and non-Arr. C-DSC + F-DSC models)

Natural and synthetic melts (including those of volcanological interest) can undergo crystallization or exsolution of volatiles on the timescale of viscosity measurements near $T_{g}$ (Liebske et al. 2003; Di Genova et al. 2017, 2020a, b). Because crystallization and dehydration around $T_{g}$ lead to the absence of pure melt viscosity data near $T_{g}$ (Dingwell 
et al. 2004; Chevrel et al. 2013), the use of DSC offers a viable route to derive melt viscosity due to its lower impact on melt chemistry and texture (Dingwell et al. 2004; Chevrel et al. 2013; Di Genova et al. 2020b; Langhammer et al. 2021; Stabile et al. 2021).

Here we use the viscosity-temperature description provided by the Mauro-Yue-Ellison-Gupta-Allan equation (MYEGA; Mauro et al. 2009): leading to a general RMSE of $0.29 \log _{10} \mathrm{~K} \mathrm{~s}^{-1}$ for DGG-1, $0.37 \log _{10} \mathrm{~K} \mathrm{~s}^{-1}$ for Di, and $0.26 \log _{10} \mathrm{~K} \mathrm{~s}^{-1}$ for N-PK52A.

Finally, Fig. 7e shows that the non-Arr. $C-D S C+F-D S C$ Model better captures the $T_{\text {onset }}$ related to the ultra-fast cooling rates from Al-Mukadam et al. (2020) due to the increased number of data considered. This reflects on a better constrain to the ultra-fast cooling region.

$\log _{10} \eta=\log _{10} \eta_{\infty}+\left(12-\log _{10} \eta_{\infty}\right) \frac{T_{g}}{T} \exp \left[\left(\frac{m_{v i s}}{12-\log _{10} \eta_{\infty}}-1\right)\left(\frac{T_{g}}{T}-1\right)\right]$

where $\log _{10}\left(\eta_{\infty}\right)$ is the limit of viscosity logarithm at infinite $T\left(-2.93 \log _{10}\right.$ Pa s, Zheng et al., 2011), $T_{g}$ is the glass transition temperature derived by DSC via a matching measurement at $10 \mathrm{~K} \mathrm{~min}^{-1}\left(T_{g} \equiv T_{\text {onset }}\right)$, and $m_{v i s}$ is the liquid fragility index (Eq. 4). Because $\eta$ and $q_{c}$ are related to each other via Eq. 8 and $K_{\text {mean }}=11.35 \log _{10}$ Pa K, from Eq. 9 we can derive:

$-\log _{10} q_{c}=-14.28+14.93 \frac{T_{g}}{T_{f}} \exp \left[\left(\frac{m_{D S C}}{14.93}-1\right)\left(\frac{T_{g}}{T_{f}}-1\right)\right]$

where $m_{D S C}$ is the calorimetric fragility (Zheng et al. 2017) according to Eq. 5. $m_{v i s}$ linearly correlates $(\sim 1: 1)$ with $m_{D S C}$ (derived by C-DSC) over a wide range of kinetic fragility (e.g., Chen et al. 2014; Zheng et al. 2017; Al-Mukadam et al. 2021b)

We consider two cases based on C-DSC data (nonArr. C-DSC Model) and C-DSC + F-DSC data (non-Arr. $C$-DSC +F-DSC Model).

For non-Arr. C-DSC model, we use $E_{a}^{q}$ (Supplementary Table 1) derived from the Arr. C-DSC Model and Eq. 5 and find $m_{D S C}=39.5$ for DGG- $1, m_{D S C}=75.5$ for N-PK52A and $m_{D S C}=73.8$ for Di. These values well match the $m_{v i s}$ provided by Al-Mukadam et al. (2020) (cf. Figure 2).

We estimate (Eq. 10) $q_{c}$ up to $1000 \mathrm{~K} \mathrm{~s}^{-1}$ with a RMSE of $0.20 \log _{10} \mathrm{~K} \mathrm{~s}^{-1}$ for DGG-1, $0.24 \log _{10} \mathrm{~K} \mathrm{~s}^{-1}$ for Di, and $0.15 \log _{10} \mathrm{~K} \mathrm{~s}^{-1}$ for N-PK52A (Table 3; Fig. 7f). The nonArr. C-DSC Model predicts $q_{c m}=637 \mathrm{~K} \mathrm{~s}^{-1}\left(2.80 \log _{10} \mathrm{~K}\right.$ $\left.\mathrm{s}^{-1}\right)$ for DGG-1, $q_{c m}=3418 \mathrm{~K} \mathrm{~s}^{-1}\left(3.53 \log _{10} \mathrm{~K} \mathrm{~s}^{-1}\right)$ for Di, and $q_{c m}=981 \mathrm{~K} \mathrm{~s}^{-1}\left(2.99 \log _{10} \mathrm{~K} \mathrm{~s}^{-1}\right)$ for N-PK52A, when the experimental $q_{c}$ is $1000 \mathrm{~K} \mathrm{~s}^{-1}$ (Table 3; Fig. 7f).

The non-Arr. C-DSC+F-DSC Model finds slightly lower fragility values. For instance, $m_{D S C}=37.1$ for DGG-1, $m_{D S C}=64.2$ for N-PK52A and $m_{D S C}=58.8$ for Di, according to a lower $E_{a}^{q}$ (Supplementary Table 1) derived from the Arr. C-DSC+F-DSC Model and Eq. 5. Here, cooling rates of $q_{c m}=414 \mathrm{~K} \mathrm{~s}^{-1}\left(2.62 \log _{10} \mathrm{~K} \mathrm{~s}^{-1}\right)$ for DGG-1, $598 \mathrm{~K} \mathrm{~s}^{-1}$ $\left(2.78 \log _{10} \mathrm{~K} \mathrm{~s}^{-1}\right)$ for Di, and $314 \mathrm{~K} \mathrm{~s}^{-1}\left(2.50 \log _{10} \mathrm{~K} \mathrm{~s}^{-1}\right)$ for N-PK52A are derived (Table 3) when the experimental $q_{c}$ is $1000 \mathrm{~K} \mathrm{~s}^{-1}$. The model underestimates F-DSC cooling rates,

\section{Comparison between models within and outside the calibration range}

The proposed models return $q_{c}$ of our melts to different extents (Fig. 7). In general, with the exception of the Arr. $C$-DSC Model, all the models can predict the experimentally imposed cooling rate with a good degree of approximation.

The Arr. C-DSC Model, based only on C-DSC, fails to predict F-DSC data due to the narrow range of $q_{c}$ employed by C-DSC $\left(\sim 0.08 \leq q_{c} \leq 0.5 \mathrm{~K} \mathrm{~s}^{-1}\right)$. This results in the unreliable extrapolation of $q_{c}$ to higher values (RMSE $=0.37 \log _{10}$ $\mathrm{K} \mathrm{s}^{-1}$ ). Conversely, the Arr. C-DSC $+F-D S C$ Model, based on C-DSC and F-DSC, allows the estimation of $q_{c}$ up to $1000 \mathrm{~K} \mathrm{~s}^{-1}$ with an RMSE $=0.16 \log _{10} \mathrm{~K} \mathrm{~s}^{-1}$ ). The Arr. $C$-DSC $+F$-DSC Model well predicts $q_{c m}$ in a $\eta\left(T_{f}\right)$ range varying between $\sim 10^{8}$ and $\sim 10^{12} \mathrm{~Pa}$ s (Supplementary Fig. 1 and Supplementary Table 1). This viscosity interval is analogous to that commonly investigated through micropenetration viscometry, where silicate melts approximate Arrhenian fluids (e.g., Hess et al. 1995).

All non-Arrhenian models proved to successfully predict $q_{c}$ in the investigated cooling rates interval. This can be achieved using the chemically independent shift factor ( $K=11.35 \pm 0.16 \log _{10} \mathrm{~Pa} \mathrm{~K}$, Eq. 8). If the viscosity-temperature relationship is known, the non-Arr. $\eta$ Model represents the most robust procedure for obtaining $q_{c}$ values (Table 3 , RMSE of $0.15 \log _{10} \mathrm{~K} \mathrm{~s}^{-1}$ ) also capturing the $T_{\text {onset }}$ related to ultra-fast $q_{c}$ from Al-Mukadam et al. (2020). Alternatively, the non-Arr. C-DSC and non-Arr. C-DSC+F-DSC Models (mean RMSE of $0.20 \log _{10} \mathrm{~K} \mathrm{~s}^{-1}$ and $0.31 \log _{10} \mathrm{~K}$ $\mathrm{s}^{-1}$, respectively) offer a viable route when viscosity data are unavailable.

Figure 8 depicts the models' performances in the entire cooling range typical of volcanic materials. The models substantially diverge, both in the slow-cooling rate $\left(q_{c}<10^{-1} \mathrm{~K} \mathrm{~s}^{-1}\right)$ and fast-cooling rate $\left(q_{c}>10^{3} \mathrm{~K} \mathrm{~s}^{-1}\right)$ regimes. It is therefore apparent that, when extensive extrapolation is needed (e.g., for the study of fast-quenched submarine materials or slow-quenched lava flows and vitrophyres), the choice of the models becomes non-trivial. 
Fig. 8 Extrapolation of the proposed models over the $q_{c}$ range of natural volcanic glasses (see Fig. 1)

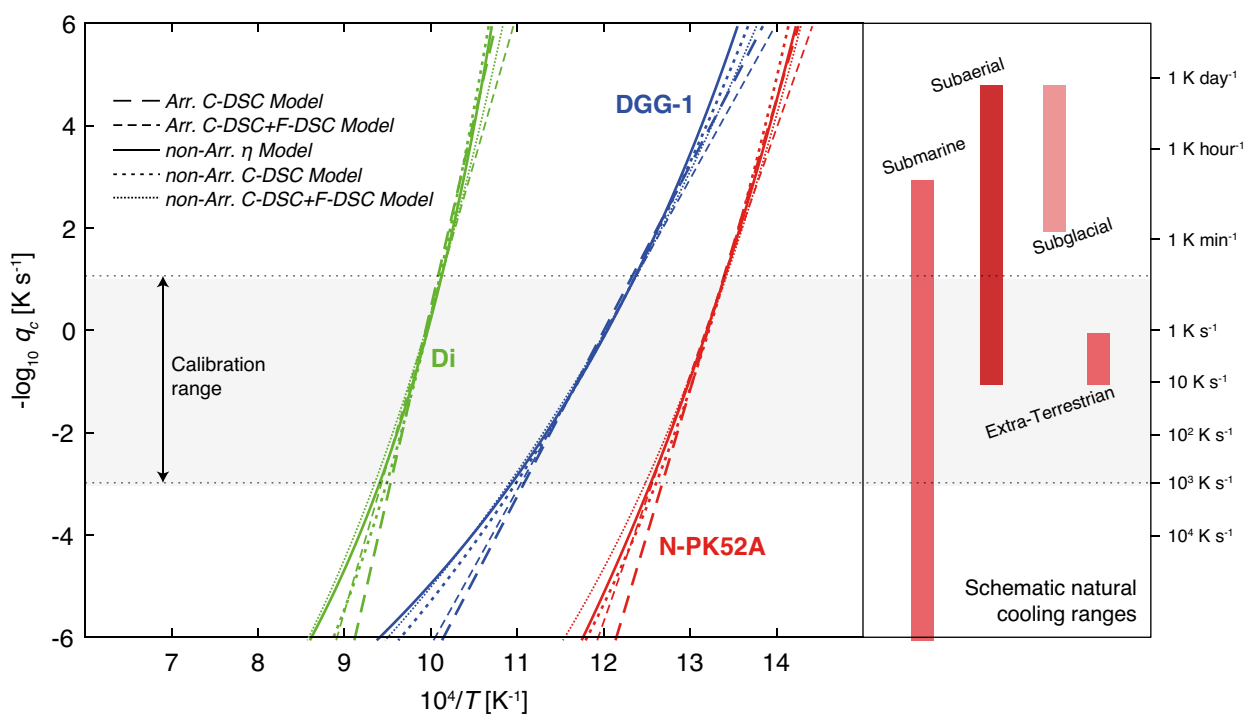

The analogy between $E_{a}^{q}$ and $E_{a}^{\eta}$ (Scherer 1984; Moynihan et al. 1996; Al-Mukadam et al. 2020, 2021a, b; Di Genova et al. 2020a, b) makes it plausible to hypothesize the $T_{f}-q_{c}$ relationship as non-Arrhenian in the entire cooling range typical of volcanic environments (Fig. 8; $10^{-5} \mathrm{~K} \mathrm{~s}^{-1} \leq q_{c} \leq 10^{6} \mathrm{~K} \mathrm{~s}^{-1}$ ), as for viscosity in the whole temperature range. As a consequence, in the case of ultrafast and ultra-slow cooling rates, the employment of a nonArrhenian model is expected to provide more reliable data and should be preferred. In contrast, the constant $E_{a}^{q}$ of Arrhenian models is expected to produce an overestimation of $q_{c}$ for fast- and slow-quenched glasses (Fig. 8).

\section{Geospeedometry recipes: a "how-to" protocol for cooling rate determination}

Figure 9 summarizes a practical "how-to" guide to determine the cooling rate of glasses, depending on the available dataset.

The choice of the appropriate calorimeter should be dictated in the first place by the expected range of cooling rates, based on the geological setting of the studied glass (Fig. 1). In addition, F-DSC is more suited when small amounts of glass material are available for the analysis and when the sample is prone to rapid modifications at high temperatures.
Fig. 9 Schematic flowchart for the determination of the unknown cooling rate embedded in glasses

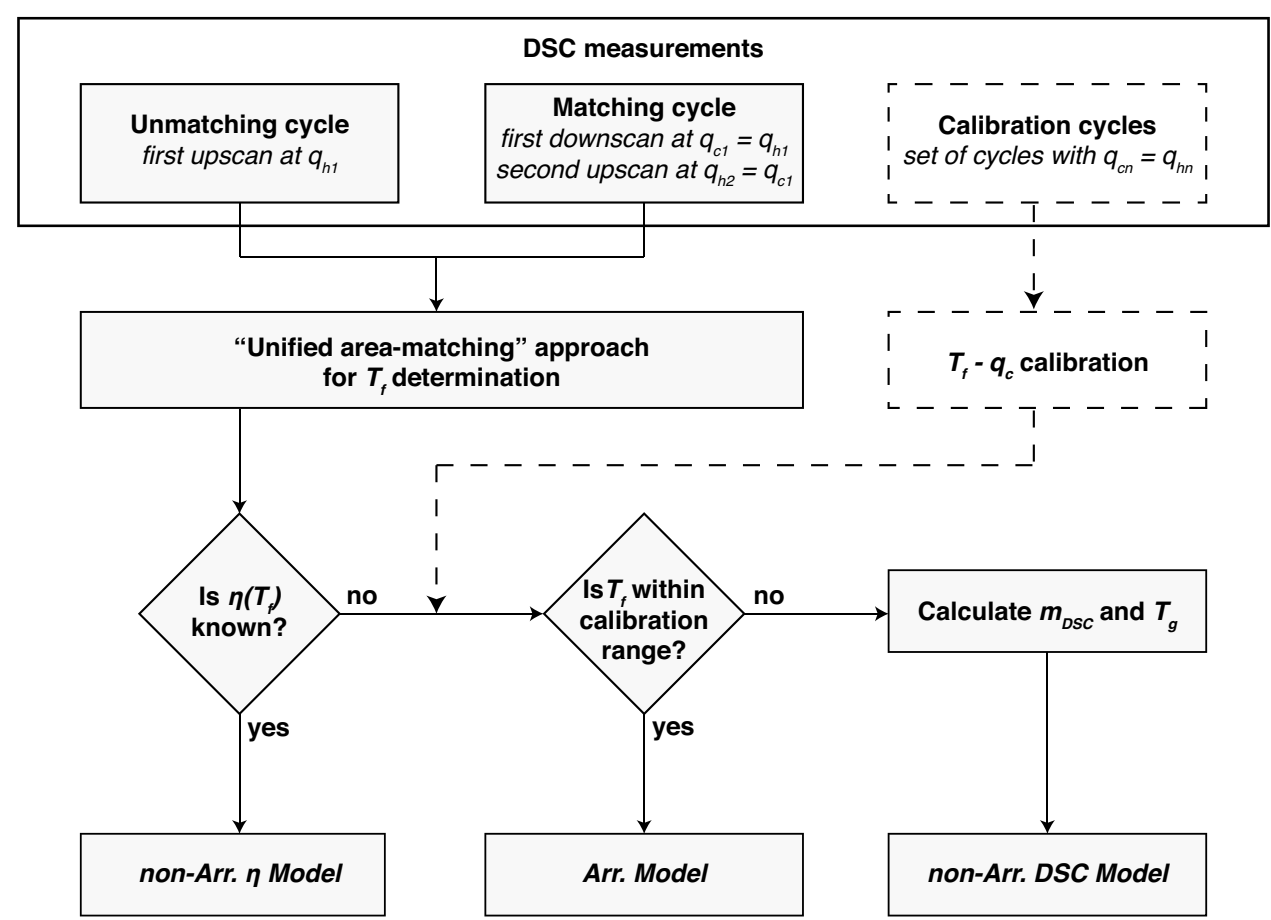


The "unified area-matching" holds for glasses subjected to $q_{c}$ between $\sim 0.08$ and $\sim 0.5 \mathrm{~K} \mathrm{~s}^{-1}$ in the C-DSC and between 3 and $1000 \mathrm{~K} \mathrm{~s}^{-1}$ in the F-DSC. The method requires two DSC upscans (unmatching and matching cycles) to estimate $T_{f}$ of the glass with unknown thermal history (Eq. 7).

A separate set of matching cycles $\left(q_{c 2, h 2}, q_{c 3, h 3}, q_{c n, h n}\right.$, ...) is required for the calibration of the $T_{f}-q_{c}$ relationship. Arrhenian models (Eq. 2) should be only used when $T_{f}$ of the glass with unknown cooling history falls within or close to the DSC (C-DSC or F-DSC) calibration range. For C-DSC measurements this conditions corresponds to $T_{f}$ close to $T_{g}$ (as defined in Eq. 1).

When a significant extrapolation is required, a nonArrhenian model represents the best protocol to estimate $q_{c}$. Notably, the non-Arr $\eta$ Model does not require the calibration of the $T_{f}-q_{c}$ relationship through matching cycles. This approach only requires two DSC measurements (i.e., the first upscan on the glass with an unknown cooling history and the rejuvenated glass matching cycle). Once $T_{f}$ is determined, the application of Eq. 8 allows the estimation of the unknown $q_{c}$, provided the viscosity of the sample is independently known.

However, crystallization and dehydration of melts may hamper the viscosity measurements (Richet et al. 1996; Liebske et al. 2003; Zheng et al. 2017, 2019; Di Genova et al. 2020a, b) and pure melt viscosity data near $T_{g}$ may be lacking. Here, the non-Arrhenian DSC-based models offer an alternative procedure for $q_{c}$ determination. The application of these models requires a C-DSC matching cycle at $q_{c, h}=10 \mathrm{~K} \mathrm{~min}^{-1}$ to constrain $T_{g}$ (Eq. $1 ; T g \equiv T_{\text {onset }}$ ) and a set of matching cycles at variable $q_{c, h}$ (C-DSC and/or F-DSC) to constrain the calorimetric fragility $\left(m_{D S C} ; \mathrm{Eq} .5\right)$. Once these parameters are determined, the unknown $q_{c}$ is computed via Eq. 10. It should be noted that these models are not constrained by data in the low-viscosity/high-cooling rates regime (a constant value of $\log _{10}\left(\eta_{\infty}\right)=-2.93$ is used in Eq. 9 and 10). Consequently, when extrapolation is needed, they are expected to perform better in the slow cooling rate regime and may progressively becomes less accurate at fast cooling rates. In addition, since the determination of $m_{D S C}$ is slightly affected by the matching calibration interval over which is averaged, the use of C-DSC should be preferred for extrapolation towards slow cooling rates, whereas the use of a F-DSC is expected to reduce the extrapolation uncertainty at very fast cooling rates (i.e., $q_{c}>10^{3} \mathrm{~K} \mathrm{~s}^{-1}$ ).

\section{Concluding remarks}

This study combined conventional and flash calorimetry to estimate the cooling rate $\left(q_{c}\right)$ of glass-forming melts over four orders of magnitude, from $0.08 \mathrm{~K} \mathrm{~s}^{-1}\left(5 \mathrm{~K} \mathrm{~min}^{-1}\right)$ to
$1000 \mathrm{~K} \mathrm{~s}^{-1}$. Our study is based on the relationship between $q_{c}$ and the glass's limiting fictive temperature $\left(T_{f}\right)$.

We demonstrate that the "unified area-matching" approach for calculating $T_{f}$ proposed by Guo et al. (2011) holds for $q_{c}$ up to $1000 \mathrm{~K} \mathrm{~s}^{-1}$. This is central for obtaining the $T_{f}$ of the glass quenched at an unknown cooling rate without the need to perform empirical fitting of heat capacity measurements.

We show that the Arrhenian extrapolation of $-\log _{10}\left(q_{c}\right)$ over $1 / T_{f}$ can overestimate the unknown $q_{c}$. The non-Arrhenian description of $-\log _{10}\left(q_{c}\right)$ over $1 / T_{f}$ offers the most accurate estimation of $q_{c}$, especially when $q_{c}$ falls outside the calibration range. The non-Arrhenian description requires, however, the knowledge of the melt viscosity. Because volcanic melt can be prone to crystallization and dehydration during viscosity measurements, we present an alternative route to derive $q_{c}$ without performing viscosity measurements.

Supplementary Information The online version contains supplementary material available at https://doi.org/10.1007/s00410-022-01899-5.

Acknowledgements This research was funded by MIUR Grants to Roma Tre PhD School in Earth Sciences (XXXIV doctoral cycle). The Grant of Excellence Departments, MIUR-Italy (ARTICOLO 1, COMMI 314-337 LEGGE 232/2016) is also gratefully acknowledged. D. Di Genova acknowledges funding by Deutsche Forschungsgemeinschaft (DFG) projects DI 2751/2-1.

Funding Open access funding provided by Roma Tre University within the CRUI-CARE Agreement.

Open Access This article is licensed under a Creative Commons Attribution 4.0 International License, which permits use, sharing, adaptation, distribution and reproduction in any medium or format, as long as you give appropriate credit to the original author(s) and the source, provide a link to the Creative Commons licence, and indicate if changes were made. The images or other third party material in this article are included in the article's Creative Commons licence, unless indicated otherwise in a credit line to the material. If material is not included in the article's Creative Commons licence and your intended use is not permitted by statutory regulation or exceeds the permitted use, you will need to obtain permission directly from the copyright holder. To view a copy of this licence, visit http://creativecommons.org/licenses/by/4.0/.

\section{References}

Al-Mukadam R, Di Genova D, Bornhöft H, Deubener J (2020) High rate calorimetry derived viscosity of oxide melts prone to crystallization. J Non Cryst Solids 536:119992. https://doi.org/10.1016/j. jnoncrysol.2020.119992

Al-Mukadam R, Zandona A, Deubener J (2021a) Kinetic fragility of pure TeO2 glass. J Non Cryst Solids 554:120595. https://doi.org/ 10.1016/j.jnoncrysol.2020.120595

Al-Mukadam R, Götz IK, Stolpe M, Deubener J (2021b) Viscosity of metallic glass-forming liquids based on $\mathrm{Zr}$ by fast-scanning calorimetry. Acta Mater 221:117370. https://doi.org/10.1016/j. actamat.2021.117370 
Angell CA (1985) Spectroscopy simulation and scattering, and the medium range order problem in glass. J Non Cryst Solids 73:1-17

Archer DG (1993) Thermodynamic properties of synthetic sapphire $\left(\alpha-\mathrm{Al}_{2} \mathrm{O}_{3}\right)$, standard reference material 720 and the effect of temperature-scale differences on thermodynamic properties. J Phys Chem Ref Data 22:1441-1453. https://doi.org/10.1063/1.555931

Bauer U, Behrens H, Fechtelkord M et al (2015) Water- and boron speciation in hydrous soda-lime-borate glasses. J Non Cryst Solids 423-424:58-67. https://doi.org/10.1016/j.jnoncrysol.2015.05.004

Behrens H (2020) Water speciation in oxide glasses and melts. Chem Geol 558:119850. https://doi.org/10.1016/j.chemgeo.2020.119850

Behrens H, Nowak M (2003) Quantification of $\mathrm{H}_{2} \mathrm{O}$ speciation in silicate glasses and melts by IR spectroscopy - in situ versus quench techniques. Phase Transitions 76:45-61. https://doi.org/10.1080/ 0141159031000076048

Benne D, Behrens H (2003) Water solubility in haplobasaltic melts. Eur J Mineral 15:803-814. https://doi.org/10.1127/0935-1221/ 2003/0015-0803

Cashman KV (2020) Crystal size distribution (CSD) analysis of volcanic samples: advances and challenges. Front Earth Sci 8:1-17. https://doi.org/10.3389/feart.2020.00291

Chen Z, Li Z, Zhang Y et al (2014) Calorimetric determination of fragility in glass forming liquids: Tf vs Tg-onset methods. Eur Phys J E 37:1-7. https://doi.org/10.1140/epje/i2014-14052-y

Chevrel MO, Giordano D, Potuzak M et al (2013) Physical properties of $\mathrm{CaAl}_{2} \mathrm{Si}_{2} \mathrm{O}_{8}-\mathrm{CaMgSi}_{2} \mathrm{O}_{6}-\mathrm{FeO}-\mathrm{Fe}_{2} \mathrm{O}_{3}$ melts: analogues for extra-terrestrial basalt. Chem Geol 346:93-105. https://doi.org/ 10.1016/j.chemgeo.2012.09.004

DeBolt MA, Easteal AJ, Macedo PB, Moynihan CT (1976) Analysis of structural relaxation in glass using rate heating data. J Am Ceram Soc 59:16-21

Di Fiore F, Vona A, Kolzenburg S et al (2021) An extended rheological map of pāhoehoe- 'A'ā transition. J Geophys Res Solid Earth 126:1-23. https://doi.org/10.1029/2021JB022035

Di Genova D, Romano C, Hess KU et al (2013) The rheology of peralkaline rhyolites from Pantelleria Island. J Volcanol Geotherm Res 249:201-216. https://doi.org/10.1016/j.jvolgeores. 2012.10.017

Di Genova D, Kolzenburg S, Wiesmaier S et al (2017) A compositional tipping point governing the mobilization and eruption style of rhyolitic magma. Nature 552:235-238. https://doi.org/10.1038/ nature 24488

Di Genova D, Zandona A, Deubener J (2020a) Unravelling the effect of nano-heterogeneity on the viscosity of silicate melts: implications for glass manufacturing and volcanic eruptions. J Non Cryst Solids 545:120248. https://doi.org/10.1016/j.jnoncrysol.2020.120248

Di Genova D, Brooker RA, Mader HM et al (2020b) In situ observation of nanolite growth in volcanic melt: a driving force for explosive eruptions. Sci Adv. https://doi.org/10.1126/sciadv.abb0413

Dingwell DB, Courtial P, Giordano D, Nichols ARL (2004) Viscosity of peridotite liquid. Earth Planet Sci Lett 226:127-138. https:// doi.org/10.1016/j.eps1.2004.07.017

Fanara S, Behrens H (2011) Proton conduction in hydrous glasses of the join $\mathrm{CaAl} 2 \mathrm{Si} 2 \mathrm{O} 8-\mathrm{CaMgSi} 2 \mathrm{O6}$ : an impedance and infrared spectroscopic study. J Chem Phys 134:194505. https://doi.org/ $10.1063 / 1.3589898$

Fulcher GS (1925) Analysis of recent measurements of the viscosity of glasses. J Am Ceram Soc 8:339-355. https://doi.org/10.1111/j. 1151-2916.1925.tb16731.x

Giordano D, Russell JK, Dingwell DB (2008) Viscosity of magmatic liquids: a model. Earth Planet Sci Lett 271:123-134. https://doi. org/10.1016/j.eps1.2008.03.038

Giuliani L, Iezzi G, Hippeli T et al (2020) The onset and solidification path of a basaltic melt by in situ differential scanning calorimetry (DSC) and ex situ investigations. Front Earth Sci 8:1-15. https:// doi.org/10.3389/feart.2020.00337
Gonnermann HM, Manga M (2012) Dynamics of magma ascent in the volcanic conduit. Model Volcan Process Phys Math Volcanism. https://doi.org/10.1017/CBO9781139021562.004

Gottsmann J, Dingwell DB (2001a) Cooling dynamics of spatter-fed phonolite obsidian flows on Tenerife, Canary Islands. J Volcanol Geotherm Res 105:323-342. https://doi.org/10.1016/S03770273(00)00262-6

Gottsmann J, Dingwell DB (2001b) The cooling of frontal flow ramps: a calorimetric study on the Rocche Rosse rhyolite flow, Lipari, Aeolian Islands, Italy. Terra Nova 13:157-164. https://doi.org/ 10.1046/j.1365-3121.2001.00332.x

Gottsmann J, Dingwell DB (2002) The thermal history of a spatterfed lava flow: the 8-ka pantellerite flow of Mayor Island, New Zealand. Bull Volcanol 64:410-422. https://doi.org/10.1007/ s00445-002-0220-7

Gottsmann J, Harris AJL, Dingwell DB (2004) Thermal history of Hawaiian pāhoehoe lava crusts at the glass transition: implications for flow rheology and emplacement. Earth Planet Sci Lett 228:343-353. https://doi.org/10.1016/j.eps1.2004.09.038

Guo X, Potuzak M, Mauro JC et al (2011) Unified approach for determining the enthalpic fictive temperature of glasses with arbitrary thermal history. J Non Cryst Solids 357:3230-3236. https://doi. org/10.1016/j.jnoncrysol.2011.05.014

Helo C, Clague DA, Dingwell DB, Stix J (2013) High and highly variable cooling rates during pyroclastic eruptions on Axial Seamount, Juan de Fuca Ridge. J Volcanol Geotherm Res 253:54-64. https:// doi.org/10.1016/j.jvolgeores.2012.12.004

Hess K-U, Dingwell DB, Webb SL (1995) The influence of excess alkalis on the viscosity of a haplogranitic melt. Am Mineral 80:297-304

Hui H, Zhang Y (2007) Toward a general viscosity equation for natural anhydrous and hydrous silicate melts. Geochim Cosmochim Acta 71:403-416

Hui H, Hess KU, Zhang Y et al (2018) Cooling rates of lunar orange glass beads. Earth Planet Sci Lett 503:88-94. https://doi.org/10. 1016/j.eps1.2018.09.019

Iezzi G, Elbrecht AL, Davis M et al (2017) Glass stability (GS) of chemically complex (natural) sub-alkaline glasses. J Non Cryst Solids 477:21-30. https://doi.org/10.1016/j.jnoncrysol.2017.09. 047

Kenderes SM, Whittington AG (2021) Faster geospeedometry: a Monte Carlo approach to relaxational geospeedometry for determining cooling rates of volcanic glasses. Chem Geol 581:120385. https:// doi.org/10.1016/j.chemgeo.2021.120385

Knoche R, Dingwell DB, Seifert FA, Webb SL (1994) Non-linear properties of supercooled liquids in the system $\mathrm{Na}_{2} \mathrm{O}-\mathrm{SiO}_{2}$. Chem Geol 116:1-16. https://doi.org/10.1016/0009-2541(94)90154-6

Kueppers U, Nichols ARL, Zanon V et al (2012) Lava balloonspeculiar products of basaltic submarine eruptions. Bull Volcanol 74:1379-1393. https://doi.org/10.1007/s00445-012-0597-x

Langhammer D, Di Genova D, Steinle-Neumann G (2021) Modeling the viscosity of anhydrous and hydrous volcanic melts. Geochem Geophys Geosyst 22:1-26. https://doi.org/10.1029/2021gc009918

Lavallée Y, Wadsworth FB, Vasseur J et al (2015) Eruption and emplacement timescales of ignimbrite super-eruptions from thermo-kinetics of glass shards. Front Earth Sci 3:1-11. https:// doi.org/10.3389/feart.2015.00002

Liebske C, Behrens H, Holtz F, Lange RA (2003) The influence pf pressure and composition on the viscocity of andesitic melts. Geochim Cosmochim Acta 67:473-485. https://doi.org/10.1016/ S0016-7037(02)01139-0

Maier CG, Kelley KK (1932) An equation for the representation of high-temperature heat content data1. J Am Chem Soc 54:3243. https://doi.org/10.1021/ja01347a029

Mauro JC, Yue Y, Ellison AJ et al (2009) Viscosity of glass-forming liquids. Proc Natl Acad Sci 106:19780-19784 
Meerlender G (1974) Viskositäts-temperaturverhalten des standardglases I der DGG. Glas Ber 47:1-3

Moynihan CT (1993) Correlation between the width of the glass transition region and the temperature dependence of the viscosity of high-Tg glasses. J Am Ceram Soc 76:1081-1087. https://doi.org/ 10.1111/j.1151-2916.1993.tb03724.x

Moynihan CT (1995) Structural relaxation and the glass transition. Rev Miner 32:1-19

Moynihan CT, Easteal AJ, De Bolt MA, Tucker J (1976) Dependence of the fictive temperature of glass on cooling rate. J Am Ceram Soc 59:12-16

Moynihan CT, Lee S-K, Tatsumisago M, Minami T (1996) Estimation of activation energies for structural relaxation and viscous flow from DTA and DSC experiments. Thermochim Acta 280:153-162

Narayanaswamy O (1971) A model of structural relaxation in glass. J Am Ceram Soc 54:491-498

Narayanaswamy OS (1988) Thermorheological simplicity in the glass transition. J Am Ceram Soc 71:900-904

Nichols ARL, Potuzak M, Dingwell DB (2009) Cooling rates of basaltic hyaloclastites and pillow lava glasses from the HSDP2 drill core. Geochim Cosmochim Acta 73:1052-1066. https://doi.org/ 10.1016/j.gca.2008.11.023

Potuzak M, Nichols ARL, Dingwell DB, Clague DA (2008) Hyperquenched volcanic glass from Loihi Seamount. Hawaii Earth Planet Sci Lett 270:54-62. https://doi.org/10.1016/j.epsl.2008. 03.018

Quane SL, Russell JK, Friedlander EA (2009) Time scales of compaction in volcanic systems. Geology 37:471-474. https://doi.org/ 10.1130/G25625A.1

Reinsch S, Nascimento MLF, Müller R, Zanotto ED (2008) Crystal growth kinetics in cordierite and diopside glasses in wide temperature ranges. J Non Cryst Solids 354:5386-5394. https://doi. org/10.1016/j.jnoncrysol.2008.09.007

Richet P, Lejeune AM, Holtz F, Roux J (1996) Water and the viscosity of andesite melts. Chem Geol 128:185-197. https://doi.org/10. 1016/0009-2541(95)00172-7

Russell JK, Giordano D, Dingwell DB (2003) High-temperature limits on viscosity of non-Arrhenian silicate melts. Am Mineral 88:1390-1394

Schawe JEK, Hess KU (2019) The kinetics of the glass transition of silicate glass measured by fast scanning calorimetry. Thermochim Acta 677:85-90. https://doi.org/10.1016/j.tca.2019.01.001

Schawe JEK, Pogatscher S (2016) Material characterization by fast scanning calorimetry: practice and applications. In: Schick C, Mathot V (eds) Fast scanning calorimetry. Springer, Berlin, pp 3-80. https://doi.org/10.1007/978-3-319-31329-0

Scherer GW (1984) Use of the Adam-Gibbs equation in the analysis of structural relaxation. J Am Ceram Soc 67:504-511

Schott (2015) N-PK52A, 266-046-0, 2015. https://www.schott.com/d/ advanced_optics/b5ef8322-fb8a-40ad-ae1b-5e8912087f1a/NPK52A_SDS_EN_V5_201505.pdf?tenant=ao-cert

Shea T, Houghton BF, Gurioli L et al (2010) Textural studies of vesicles in volcanic rocks: An integrated methodology. J Volcanol Geotherm Res 190:271-289. https://doi.org/10.1016/j.jvolgeores. 2009.12.003

Stabile P, Sicola S, Giuli G et al (2021) The effect of iron and alkali on the nanocrystal-free viscosity of volcanic melts: a combined Raman spectroscopy and DSC study. Chem Geol 559:119991. https://doi.org/10.1016/j.chemgeo.2020.119991

Tammann G, Hesse W (1926) Die Abhängigkeit der Viscosität von der Temperatur bie unterkühlten Flüssigkeiten. Zeitschrift Für Anorg Und Allg Chemie 156:245-257. https://doi.org/10.1002/ zaac.19261560121

Tool AQ (1946) Relation between inelastic deformability and thermal expansion of glass in its annealing range. J Am Ceram Soc 29:240-253
Tool AQ, Eichlin CG (1931) Variations caused in the heating curves of glass by heat treatment. J Am Ceram Soc 14:276-308

Vasseur J, Wadsworth FB, Lavallée Y et al (2013) Volcanic sintering: timescales of viscous densification and strength recovery. Geophys Res Lett 40:5658-5664. https://doi.org/10.1002/2013G L058105

Vetere F, Iezzi G, Behrens H et al (2015) Glass forming ability and crystallisation behaviour of sub-alkaline silicate melts. EarthScience Rev 150:25-44. https://doi.org/10.1016/j.earscirev.2015. 07.001

Vogel H (1921) Das temperaturabhängigkeitsgesetz der viskosität von flüssigkeiten. Phys Z 22:645-646

Wadsworth FB, Vasseur J, Schauroth J et al (2019) A general model for welding of ash particles in volcanic systems validated using in situ X-ray tomography. Earth Planet Sci Lett 525:115726. https://doi. org/10.1016/j.epsl.2019.115726

Webb SL (2021) Thermal stress, cooling-rate and fictive temperature of silicate melts. Contrib Miner Pet 176:1-9. https://doi.org/10. 1007/s00410-021-01836-y

Webb SL, Knoche R, Dingwell DB (1992) Determination of silicate liquid thermal expansivity using dilatometry and calorimetry. Eur J Mineral 4:95-104

Wilding MC, Webb SL, Dingwell DB (1995) Evaluation of a relaxation geospeedometer for volcanic glasses. Chem Geol 125:137-148. https://doi.org/10.1016/0009-2541(95)00067-V

Wilding MC, Webb SL, Dingwell DB (1996a) Tektite cooling rates: caolorimetric relaxation geospeedometry applied to a natural glass. Geochim Cosmochim Acta 60:1099-1103

Wilding MC, Webb SL, Dingwell DB et al (1996b) Cooling rate variation in natural volcanic glasses from Tenerife, Canary Islands. Contrib Miner Pet 125:151-160. https://doi.org/10.1007/s0041 00050212

Wilding MC, Dingwell DB, Batiza R, Wilson L (2000) Cooling rates of hyaloclastites: applications of relaxation geospeedometry to undersea volcanic deposits. Bull Volcanol 61:527-536. https:// doi.org/10.1007/s004450050003

Wilding MC, Smellie JL, Morgan S et al (2004) Cooling process recorded in subglacially erupted rhyolite glasses: rapid quenching, thermal buffering, and the formation of meltwater. J Geophys Res Solid Earth 109:1-13. https://doi.org/10.1029/2003JB002721

Yue YZ, Christiansen JD, Jensen SL (2002) Determination of the fictive temperature for a hyperquenched glass. Chem Phys Lett 357:20-24. https://doi.org/10.1016/S0009-2614(02)00434-7

Yue Y, der Ohe R, Jensen SL (2004) Fictive temperature, cooling rate, and viscosity of glasses. J Chem Phys 120:8053-8059. https://doi. org/10.1063/1.1689951

Zhang Y, Jenkins J, Xu Z (1997) Kinetics of the reaction $\mathrm{H}_{2} \mathrm{O}+\mathrm{O}$ $\leftrightarrow 2 \mathrm{OH}$ in rhyolitic glasses upon cooling: geospeedometry and comparison with glass transition. Geochim Cosmochim Acta 61:2167-2173

Zhang Y, Xu Z, Behrens H (2000) Hydrous species geospeedometer in rhyolite: improved calibration and application. Geochim Cosmochim Acta 64:3347-3355. https://doi.org/10.1016/S00167037(00)00424-5

Zheng Q, Mauro JC, Yue Y (2017) Reconciling calorimetric and kinetic fragilities of glass-forming liquids. J Non Cryst Solids 456:95-100

Zheng Q, Zhang Y, Montazerian M et al (2019) Understanding glass through differential scanning calorimetry. Chem Rev 119:78487939. https://doi.org/10.1021/acs.chemrev.8b00510

Publisher's Note Springer Nature remains neutral with regard to jurisdictional claims in published maps and institutional affiliations. 